\title{
Research
}

\section{Environmental Licensing and Land Aggregation: An Agent-Based Approach to Understanding Ranching and Land Use in Rural Rondônia}

\author{
$\underline{\text { Andrew Reid Bell }}^{1}$
}

\begin{abstract}
Agricultural development and climate change will be two of the major stressors on the Amazon natural-human system in the decades to come. Environmental licensing for rural properties is being implemented in several states in the Brazilian Amazon with the goal of restoring forests in agricultural landscapes and mediating the impacts of these stressors. This study presents an agent-based model of ranching and land exchange, informs it with empirical results from social research in the Ji-Paraná River Basin, Rondônia, Brazil, and investigates the social, economic, and environmental outcomes that can be expected as a result of environmental licensing in the context of climate change. Model results informed by these data suggest that although an environmental licensing scheme with monitoring and enforcement may increase the level of forested land in ranching landscapes, it may do so at the expense of the small producer. To the extent that effective monitoring and enforcement exist, a focus on larger holdings will help to mediate this negative social impact. These results suggest that a middle ground can be found in cases where current environmental goals conflict with legacies of past colonization and resource-use regimes.
\end{abstract}

Key Words: agent-based modeling; Amazon; coupled natural-human system; environmental licensing; farm structural change; land-use change

\section{INTRODUCTION}

Two major stressors on the Amazon natural-human system are an advancing frontier of agricultural development and global climate change. The agricultural frontier, driven into the Amazon by the aggressive colonization policy in the 1970s, waves of migration of poor landless peasants, and growing domestic markets for beef and international markets for soy (Simon and Garagorry 2005), threatens the Amazon system by clearing trees, destroying habitat, polluting water, and displacing indigenous peoples. In regions along the frontier, the presence of roads and land speculation are commonly cited as the major proximate drivers of land-use change (Faminow 1997, Caviglia-Harris 2004, Soares et al. 2004). Where access is created, small and large farms alike claim new land far from current markets in the expectation that further frontier expansion will drive up the land's value, though this 'dragging effect' (Fearnside 2007) has been demonstrated to be most strong when moderate levels of local infrastructure already exist (Pfaff 1999, Pfaff et al. 2007). Behind the advancing frontier, where most land parcels have been claimed or allocated, the conversion of forest into agricultural use or disuse is in the hands of the property owner. Environmental licensing for rural properties is emerging in several Brazilian Amazon states as a means of regulating land use on active agricultural properties (Lima et al. 2005, ambientebrasil 2010). However, the ability or willingness of a rural producer to maintain forested lands on his or her property may depend strongly on cost structure and the ability to turn a profit from the remaining productive land, which in turn is a function of farm size (Ellis 1993). This is a constraint for any attempts to regulate land use in the region because for smaller properties, stringent environmental regulations may mean either an inability to comply, or an inability to remain in production. 
The Amazon Region will be affected in the coming decades by climate change. Simulation results from the most recent International Panel on Climate Change report in 2007 suggest it will be warmer, and probably drier, and there is an expected rise in the frequency of extreme weather events, i.e., longer droughts and stronger storms (Magrin et al. 2007). One impact, on large and small farms alike, will be to make agricultural activity, such as raising cattle on pasture, more expensive because vegetation growth is negatively affected. By simultaneously restricting the area of, and reducing the productivity by, active agricultural land, the joint stressors of environmental licensing and climate change have the potential to pressure production in the rural Amazon.

This study develops an agent-based model of a ranching landscape to investigate the potential social, economic, and environmental outcomes of a new environmental licensing scheme being implemented in the state of Rondônia, under the additional stressor of a change in climate. Agentbased analysis of changes in farm structure is a relatively new field of research (Zimmermann et al. 2009), and the model in this study incorporates features of particular relevance to the Amazonian context, i.e., land sale by struggling farmers and climate variability, that have not appeared in other agent-based approaches to farm change. The coupled model of ranching and climate asks whether the joint pressures of licensing and a changed cost structure due to climate change will act to force producers on small properties off of their land, and whether this social impact can be mediated while still achieving landscape-scale land-use goals.

This study finds that environmental goals can be harmonized with social and economic goals in the ranching landscape, but that this will require particular care in implementation, with monitoring programs that emphasize larger properties. The current work will be of value both to the nascent literature on agent-based approaches to analyzing rural policy, and to the broader discussion within natural resource management of how, in a socially just manner, to match today's goals for environmental and ecological services with the legacies of colonization and resource-exploitation regimes of the past.

\section{BACKGROUND}

\section{Ranching and environmental licensing}

This study focuses on ranching, the dominant agricultural land use in Rondônia, with 5,000,000 ha of pasture compared with only 500,000 ha of cropland in 2006 (IBGE 2006). The rates of landuse change across properties of different sizes in Amazônia tend to be different, with smaller plots needing to deforest proportionally more of their lots than larger plots to meet needs (Aldrich et al. 2006, D'Antona et al. 2006). There is a broad distribution of property size in Ronônia, with nearly 30 properties greater than 2000 ha in size declared in the 1996 Census, along with more than 15,000 properties smaller than 100 ha and hundreds in between (IBGE 1996). There is also a slow process of land aggregation in the Amazon, with many smaller ranchers selling land to meet financial obligations (D'Antona et al. 2006). If climate change affects the profitability of ranching activity, it is reasonable to expect that there will be some impact on the extent of land sale among ranchers. To the extent that ranchers operating at different scales of production deforest at different rates and maintain their land in different ways (Ewers and Laurance 2006), it is reasonable to expect that changes in land distribution will affect environmental outcomes beyond the direct impacts brought about by an increase in storms and droughts.

To confront the environmental problems brought about by land-use change, the State Secretariat for Environmental Development (SEDAM-RO) is following other states in the Amazon region in implementing a program of environmental licensing for rural properties, the Licenciamento Ambiental em Propriedade Rural (LAPRO; SEDAM-RO 2008). At present, to receive any form of rural credit from Brazilian banks, property owners must obtain an environmental license, or for some smaller property owners, simply declare that their properties are in accordance with law. Eventually, SEDAMRO plans to close off access to markets for those properties not licensed. To obtain a license, rural property owners must generate a management plan for recuperation of forests over a 30-year period in areas of permanent preservation (APP), including riparian buffer strips along all watercourses and forests on all steep hill slopes, and legal reserve (LR). 
The requirements for LR are a point of tension for SEDAM-RO; under LAPRO, properties with less than $50 \%$ of land in LR prior to 1998 must recuperate up to $50 \%$ within the 30 -year period. In contrast, owners wishing to clear new land on property that was forested as of 2005 must maintain $80 \%$ of the land as LR, a move that clearly favors those who have already committed infractions. Further, to many, the requirements of LAPRO feel like a complete reversal by the state; although on paper the Federal Forest Code has long required rural property owners to maintain $50 \%$ of their land as $\mathrm{LR}$, in practice, colonization policies that brought many farmers to the region in the 1970s and 1980s rewarded those who added value to their land by clearing it (Hecht and Cockburn 1989, Fearnside 2001). For large cattle ranchers not currently possessing $50 \%$ LR, licensing will mean a big drop in income; for many smaller family properties, licensing that requires proportionally the same from them as from large properties may mean their properties will become unviable as the sole sources of income to maintain the household. Although a number of activities implementing agroforestry systems (SAF) are permitted within APP and LR, including rubber, açai palm, and coffee, there is no guarantee that many of these small farmers have the resources or skills to switch to these activities, or that markets will support them.

A number of proposals have arisen recently to try to minimize the way in which LAPRO will affect the small farmer. One proposal being put forward by several organizations in the state proposes a modification to the Forest Code such that:

1. All farms up to one fiscal module (60 hectares) in size would be required to restore riparian forests along watercourses.

2. All farms between one and two fiscal modules (120 hectares) in size would be required to restore riparian forests along watercourses and maintain $20 \%$ of the property in legal reserve forest.

3. All farms greater than two fiscal modules in size (>120 hectares) would be required to restore riparian forests along watercourses and maintain $50 \%$ of the property in legal reserve forest (de Jesus 2009).

The goal of this paper is to investigate the ways in which climate change and LAPRO will affect environmental quality, measured through the fraction of land that is forested; the profitability of ranching in the region, measured by the average profit earned per hectare of property per year; and social equity, measured by distribution of land among farmers. Additionally, this paper will investigate the ways in which modification of the Forest Code or LAPRO may shift how small farmers are affected by licensing requirements. Although programs like LAPRO may help to restore critical environmental services in rural areas, it is important to consider in detail the burdens that they place on rural production.

This paper tests the following hypotheses, regarding the impacts of climate change and environmental licensing on the rancher-water coupled naturalhuman system: (H1) decreases in precipitation will drive increased rates of land aggregation; $(\mathrm{H} 2)$ environmental licensing will lead to better environmental outcomes on properties currently lacking significant forest cover; (H3) reduced access to markets through environmental licensing will drive increased rates of land aggregation; and (H4) reduced licensing requirements for small properties will lead to lower rates of land aggregation.

\section{Agent-based modeling in agriculture: filling a current gap}

The last decade has seen the development of several agent-based approaches to looking at farm production and change (Berger 2001, Parker et al. 2003), but they are still relatively uncommon (Zimmermann et al. 2009). The model in the literature that most closely relates to the current work, looking at the ties between policy and farm structural change, is the AgriPoliS model of Happe et al. (2008), a sophisticated agent-based approach to rural economics problems that allows farmer agents to make technological and structural change to their farms by purchasing equipment and renting additional plots, and to make land-use choices in response to shifts in policy, prices, and costs (Happe et al. 2006). Developed to look at European, with particular attention to German, agriculture, AgriPoliS has been applied to several policyrelevant issues in common with the current study, i.e., the effect of a switch in policy regime on farm structure (Happe et al. 2008), and the factors that may cause farmers to leave the agricultural landscape (Happe et al. 2009). 
However, AgriPoliS lacks the capacity to model several of the features that characterize the Amazonian frontier and postfrontier agricultural landscapes. First, although land rental does occur, land purchase and aggregation under successful farmers is much more common than in the European context for which AgriPoliS was developed. Second, climate variability, one of the focal stressors in the current study, is an important decision making factor for local farmers, and strongly shapes the productive capacity of pastures for cattle. Most ranchers in the sample reported using pasture conditions rather than market prices as the primary decision factor in stocking pasture. A model of the Rondônian postfrontier ranch landscape must incorporate the local practice of selling off land parcels to cover financial needs, as well as the link between climate, pasture productivity, and rancher decision making. The model developed for this study fills this particular gap.

\section{METHODS}

This study employs an agent-based model of a ranching landscape, informed by and validated through survey data collected from February to April 2009. The survey was applied to a sample of 241 small to medium cattle producers (up to 320 hectares in size) from three municipalities, i.e., JiParaná, Cacoal, and Machadinho do Oeste, in the Ji-Paraná River Basin in Rondônia, Brazil (Fig. 1). Farmers were interviewed as they visited local offices of the state agency for rural extension services, EMATER-RO, and the sample was poststratified by size. Rondônia boasts the most intensive agricultural production of the Amazonian states with $37 \%$ of its land committed to pasture and cropland (IBGE 2006). Within Rondônia, the JiParaná Basin is the most developed, for example, most of the length of the BR-364 highway in Rondônia passes through the basin, and is an ideal site to investigate cattle ranching.

The survey research yielded important baseline data with which to inform and calibrate the agent-based model. Specifically, data on the use and ownership of tractors, as an indicator of mechanization, on the rate of recuperation of pasture and the annual maintenance costs incurred, on the annual costs to supplement cattle diets during drought, and on the kinds of information used to decide how many cattle to stock in pastures were obtained. These data, and the role they played in informing model development, i.e., directly translated to a model parameter or interpreted in concert with other literature or anecdotal data, are given in the full model description (Appendix 1) and the section on calibration and validation (Appendix 2). Where available, other data to parameterize the model were obtained or interpreted from literature sources; where source data were unavailable, reasonable parameter values are assumed. These parameters, and explanations of their source and interpretation, are summarized in Appendix 3.

\section{Model summary}

Full source code for the following model, implemented in MATLAB, is available as Appendix 4 to this study. The following is a summary of model logic; the complete description of model mechanisms and state equations, along with data on land use and mechanization from the sample by which the model is informed, can be found in Appendix 1.

Rancher agents raise cattle on an $n x m$ grid of land representing a rural Amazon watershed. Each agent begins with an allocation of grid cells, with land in each cell allocated entirely to pasture, the source of grass for cattle growth. Cattle consume grass to meet their dietary needs when grass growth is sufficient to support them; when grass growth is insufficient, such as during a drought, ranchers must purchase supplements to meet cattle needs. This simple mechanism captures the idea that rather than selling cattle off as a first response, ranchers may pay nominal costs to maintain cattle health during drought periods, a practice observed in our sample through the purchase of supplements, commitment of land to the growing of sugar cane leaves for cattle, or by the renting out of under-utilized neighboring pastures.

At each time period, rancher agents choose to modify a portion of their land, i.e., clearing forest for pasture and restoring degraded pasture to pasture or pasture to forest, to stock their land with cattle, and to purchase or sell land from their neighbors. Land-use change decisions are made based on the present value of land under the particular use with a discount rate $d$, and conversion is limited by both the financial and time resources of the agent. Ranchers who fall into financial deficit sell cattle and land to attempt to remain solvent. Parcels of 
Fig. 1. Ji-Paraná River Basin

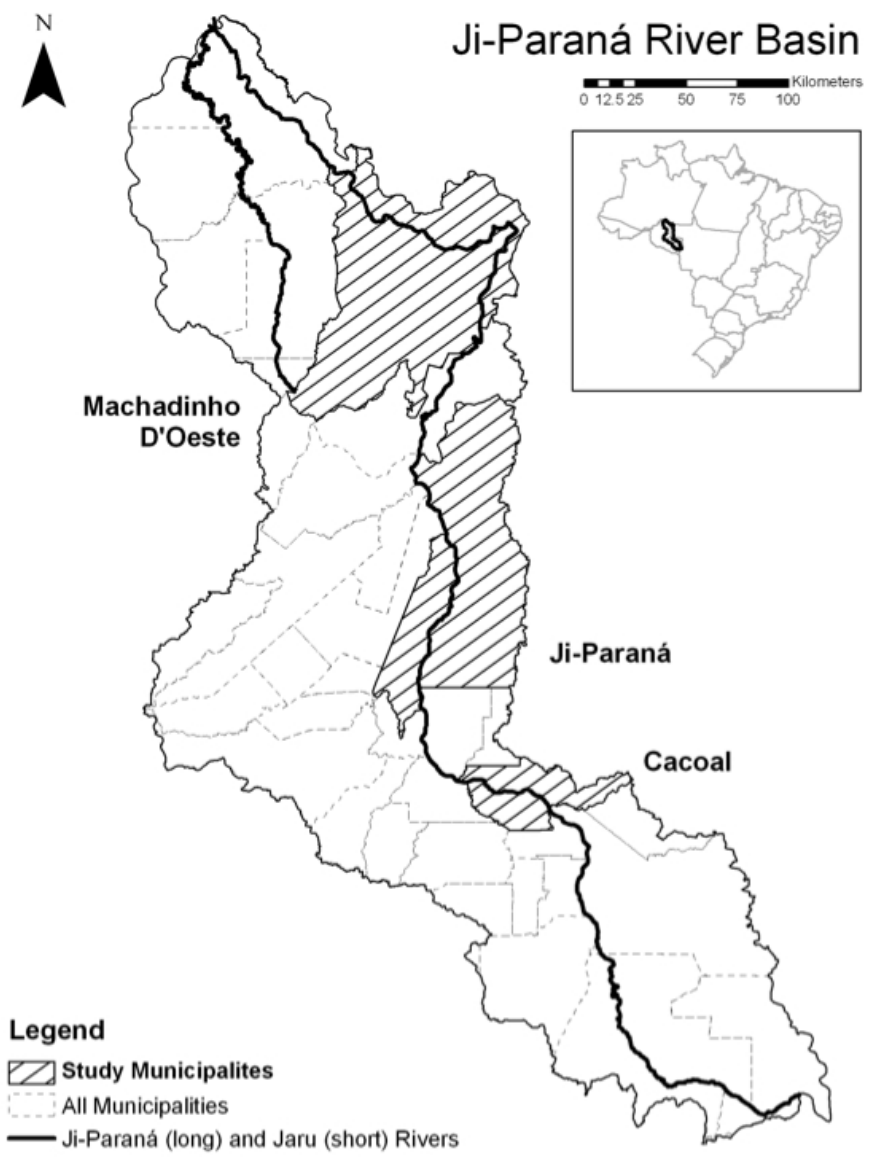

land put up for sale are auctioned to the highest bidder among neighbors of the property from which the parcel is being taken. The cattle stocking rate is a function of the grass growth rate.

After an initial start up period of 10 years, an environmental licensing program is implemented for the remaining 30 years of the simulation (Fig. 2). Under the license, ranchers must achieve a set level of reforestation each year to maintain their licenses and enjoy the premium market price that is given only to license holders. A random selection of agents is monitored at each time step, and those ranchers that are far off from meeting their licensing obligations may lose their licenses. The selection of agents is made by a uniform random selection of grid cells, so that larger properties are more likely to be fined. Agents are informed of the monitoring of other ranchers by communicating with other ranchers in the landscape, which in turn informs their expected incomes when calculating the present value of each land use. The strength of communication among agents is thus a determinant of how well ranchers can predict the expected costs of clearing forest. All ranchers share a network link with all other ranchers, they are a 'clique' in the network sense; the strength of each link, i.e., the likelihood that a rancher will communicate with another particular rancher in a time period, is normally distributed.

Daily precipitation is drawn from exponential distributions of mean $\lambda_{i}$, with a different $\lambda_{i}$ for each month $\mathrm{i}$ of the year. Climate change is treated as an equal, fractional decrease in all $\lambda_{i}$ and thus, in overall annual precipitation. The direct impact of climate change is to increase supplement costs for cattle diets during drought periods. 
Fig. 2. Land use for a typical model run $(\Delta \mathrm{Prec}=0 ; \Delta \mathrm{EI}=0.25$; Tiered Environmental Licensing $)$. Green indicates forest, yellow pasture, and brown degraded pasture. A) Time = 1 year; B) Time $=10$ years; C) Time $=30$ years. Note that land owned by a failing ranch at year 10 (brown L-shape in B) has been bought out by neighboring farms by year 30 .

A

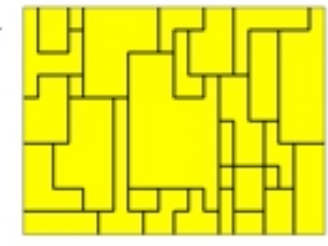

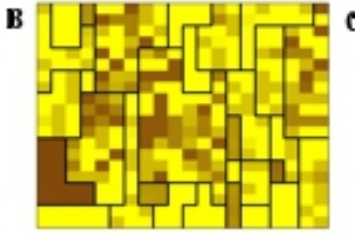

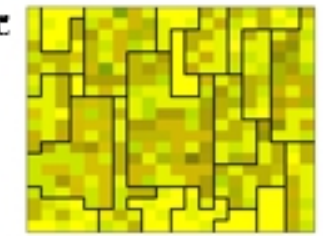

In the experiments discussed below, ranchers are granted an initial allocation of land based on the distribution of properties observed in the field sample from the Ji-Paraná Basin. During an initial start up period of 10 years, no charges are levied or land sales permitted while ranchers stock their land and clear away forest to make room for more pasture. At the 10-year mark, land sales are permitted, monitoring and enforcement for licenses begins, and the model is run for an additional 30year period. Ranchers must continually reforest their property, at a rate that allows them to meet the established goals by the end of the 30 -year period, to keep their licenses. The outcome for each experiment at the end of this period is measured by the forested fraction of the landscape, the average profit per hectare of property per year, and the distribution of land among all ranchers originally present on the land.

\section{EXPERIMENTS}

This study presents results from a set of experiments across 12 scenarios: four sets of assumptions about the structure and value of rancher networks and communication for each of three policy scenarios.

\section{Experiment structure}

For each of the 12 scenarios, a set of $n=10$ replicate model runs with different seeds was performed across the values of the independent variable pairs $\Delta_{\mathrm{EI}}$ and $\Delta_{\text {Prec }}$ (in scenarios 1 and 2) and $\Delta_{\mathrm{EI}}$ and $\mathrm{p}_{\mathrm{mon}}$ (in scenario 3 ) to generate a response surface (Table
1). The dimension $D_{E I}$ represents the fractional change in expected income from the sale of cattle when not in possession of a license, and is a signal of how strictly market access for those without licenses is controlled. The price ranchers without licenses obtain for cattle is simply $\left(1-\mathrm{D}_{\mathrm{EI}}\right)$ times the market price. The dimension $\mathrm{D}_{\text {Prec }}$ represents the change in overall precipitation relative to the base case; in month $i$, precipitation is drawn from an exponential distribution with mean $\left(1-\mathrm{D}_{\text {Prec }}\right) 1_{\mathrm{i}}$. The dimension $\mathrm{p}_{\text {mon }}$ represents the likelihood of a particular grid cell being targeted for a site visit, and is a signal of effort invested into monitoring.

The total number of runs for each response surface is $11 \times 11 \times 10=1210$ runs.

\section{Policy scenarios}

The first two of the three scenarios investigate the interaction of the $\Delta_{\mathrm{EI}}$ and $\Delta_{\text {Prec }}$ stressors across two different implementations of environmental licensing, a basic approach, and an approach with tiered requirements for farms of different sizes. The goals of the licensing are treated in terms of a target fraction of forest cover at the end of the 30-year licensing period, $\mathrm{f}_{\text {targ,final }}$, so that the two approaches are:

1. Constant licensing requirements for all properties $\left(f_{\text {targ,final }}=0.5\right.$ for all property sizes $)$

2. A tiered licensing system favoring the small producer. The study assumes that riparian forest along watercourses takes up about $10 \%$ 
Table 1. Values for independent variables $\Delta \mathrm{EI}$ and $\Delta \mathrm{Prec}$ in response surfaces for policy scenarios 1 and 2 , and for independent variables $\Delta \mathrm{EI}$ and $\mathrm{p}_{\mathrm{mon}}$ in response surfaces for policy scenario 3 .

\begin{tabular}{lll}
\hline \hline Scenario & Variable & Values \\
\hline \multirow{3}{*}{1 and 2} & Proportional change in income $\Delta_{\mathrm{EI}}$ & 0 to 0.5 in increments of 0.05 \\
& Change in precipitation $\Delta_{\mathrm{Prec}}$ & 0 to -0.1 in increments of 0.01 \\
& Proportional change in income $\Delta_{\mathrm{EI}}$ & 0 to 0.5 in increments of 0.05 \\
& Probability of selection for monitoring $\mathrm{p}_{\text {mon }}$ & $0,0.01,0.02,0.03,0.04,0.06,0.08,0.16$, \\
& & $0.24,0.32,0.48$
\end{tabular}

of properties up to 120 ha in size, and can totally be contained within the $50 \%$ legal reserve for larger properties, so that the tiered licensing described earlier becomes:

$f_{\text {targ,final }}=0.1$ for properties smaller than or equal to 60 ha,

$\mathrm{f}_{\text {targ.final }}=0.3$ for properties less than or equal to 120

hectares but greater than 60 hectares, and

$\mathrm{f}_{\text {targ,final }}=0.5$ for properties larger than 120 ha

The third scenario returns to the basic, nontiered licensing of scenario 1 and investigates trading off effort in monitoring and enforcement while holding climate constant. In both of scenarios 1 and 2 , $\mathrm{p}_{\text {mon }}$ (the probability of a grid cell being selected and the corresponding property monitored) was set to 0.075 , meaning that a property composed of 10 cells, for example, had a $7.5 \%$ chance of being monitored in a given year. In scenario $3, \Delta_{\mathrm{EI}}$ and $\mathrm{p}_{\mathrm{mon}}$ are varied to investigate the way in which these two parts of the monitoring and enforcement process (site monitoring and the control of market access) may substitute for one another within the basic, nontiered case.

\section{Rancher scenarios}

In each policy scenario outcomes are evaluated across four scenarios of rancher networks, based on two dimensions of communication strength and size effect (Table 2). These dimensions arise from two major assumptions to be made about how ranchers interact in the system: first, that they interact to exchange information, e.g., about costs, practices, or having their site monitored, etc., and second, that they interact to share labor and equipment, thus cutting their costs and allowing them to act like larger, more mechanized farms. Over $75 \%$ of the sample reported membership in local rural syndicates and producers associations, and many reported that this membership gave them access to equipment and discounts they would not otherwise have. However, the survey did not otherwise shed much light on the extent to which these assumptions of information, labor, and equipment sharing might be true in the region.

Communication strength refers to the mean strength of connections among ranchers in the system, and thus the probability that a given pair of ranchers will share information, such as about land values or levied fines. Size effect refers to the extent to which ranchers who share a strong connection also share resources, e.g., labor, tractors, etc., and is thus a measure of how well smaller farms are able to act, from a cost and land-use perspective, like larger farms. The mathematical details of these scenarios are presented in the model description in Appendix 1.

Lacking precise knowledge of how well networked ranching communities may be, or how costs may vary across scale, an exploration of these alternative scenarios sheds insight into the ways that communication and economies of scale may affect the trajectories of land aggregation and environmental quality throughout the simulations.

The complete set of experiments, i.e., four rancher network scenarios within each of three policy 
Table 2. Values for independent variables $q$ and pbase in rancher network scenarios.

\begin{tabular}{lll}
\hline \hline & Low Size Effect & High Size Effect \\
\hline Low Communication & $\begin{array}{l}\text { Network links are weak, so that risks of being } \\
\text { monitored as well as information about costs is } \\
\text { poorly communicated. Network links confer } \\
\text { little advantage in the way of reducing costs. }\end{array}$ & $\begin{array}{l}\text { Network links are weak, so that risks of being } \\
\text { monitored as well as information about costs is } \\
\text { poorly communicated. Where they do exist, } \\
\text { network links significantly help reduce costs, } \\
\text { such that some small properties experience costs } \\
\text { and limitations similar to larger properties. }\end{array}$ \\
& $\begin{array}{l}\text { Network links among ranchers are strong so } \\
\text { that the risk of being monitored is well } \\
\text { communicated and understood. Network links } \\
\text { confer little advantage in the way of reducing } \\
\text { costs. }\end{array}$ & $\begin{array}{l}\text { Network links among ranchers are strong. } \\
\text { Network links also help farmers significantly } \\
\text { reduce their costs, i.e., through shared labor and } \\
\text { equipment, making their effective farm sizes } \\
\text { much larger. In this scenario, small ranches } \\
\text { experience costs and limitations similar to larger } \\
\text { properties, so that there is no real economy of } \\
\text { scale. }\end{array}$ \\
\hline
\end{tabular}

scenarios, and 1210 experimental runs to generate the surfaces in each experiment, results in a total number of $3 \times 4 \times 1210=14520$ experimental runs.

\section{EXPERIMENTAL RESULTS}

Figures 3 through 6 present the three outcomes of (1) fractional forest cover, (2) average profit per year per hectare of land, and (3) property GINI for the rancher scenario of low communication and low size effect; the complete set of results across all rancher scenarios is included as Appendix 5.

The state of land aggregation in the basin is expressed as a 'GINI' coefficient in the model results. The formula for the property size distribution GINI is:

$$
G I N I_{\text {property }}=\frac{2 \sum_{i=1}^{n} i A_{i}}{n \sum_{i=1}^{n} A_{i}}-\frac{n+1}{n}
$$

where $A_{i}$ is the size of a ranch and $n$ is the total number of ranches. This coefficient ranges from close to 0 , implying a more even distribution of land among ranchers, to 1 , signifying most or all land concentrated under a single or small number of ranchers.

\section{Joint pressures of environmental licensing and climate}

In the nontiered environmental licensing scenario, there is some support for hypothesis H2, that licensing can in fact bring about better forest outcomes on denuded properties (forested fraction initially rises as $\mathrm{D}_{\mathrm{EI}}$ increases from 0 in all scenarios and for all tested levels of $D_{\text {Prec }}$; Fig. 3). However, this comes at the expense of revenue, i.e., average per hectare profits strictly decrease as the market price available to nonlicensed properties drops. Above some threshold value of $\mathrm{D}_{\mathrm{EI}}$, profits on average drop below 0 , and ranchers do not have the resources to commit to forest restoration or even their own ranching. Forested fraction peaks and then decreases as the stricter environmental licensing makes ranching unviable.

Moving along the dimension of decreasing precipitation, the peak forested fraction that is achieved drops, suggesting a lack of resources to commit to forest restoration, which in turn is reflected by the smooth decrease in average profits per hectare as $\mathrm{D}_{\text {Prec }}$ drops further.

Overall, higher forested fractions are achieved when network connectivity is high, i.e., when ranchers are better able to assess the risk of having a license stripped and their perceived opportunity cost of losing the license is much higher (Fig. D.1). Put 
Fig. 3. Response surfaces for Policy Scenario 1 (nontiered environmental licensing), Rancher Scenario 1 (low networking, low size effect) showing sensitivity to change in expected income $\Delta \mathrm{EI}$ and in precipitation $\triangle$ Prec. (A) Average forested fraction across the landscape; (B) Average profit per hectare of property per year; (C) Level of land aggregation measured by the property GINI coefficient. Response surfaces for Rancher Scenarios 1-4 are shown in Appendix 5, as are surfaces for the standard deviations across repetitions.
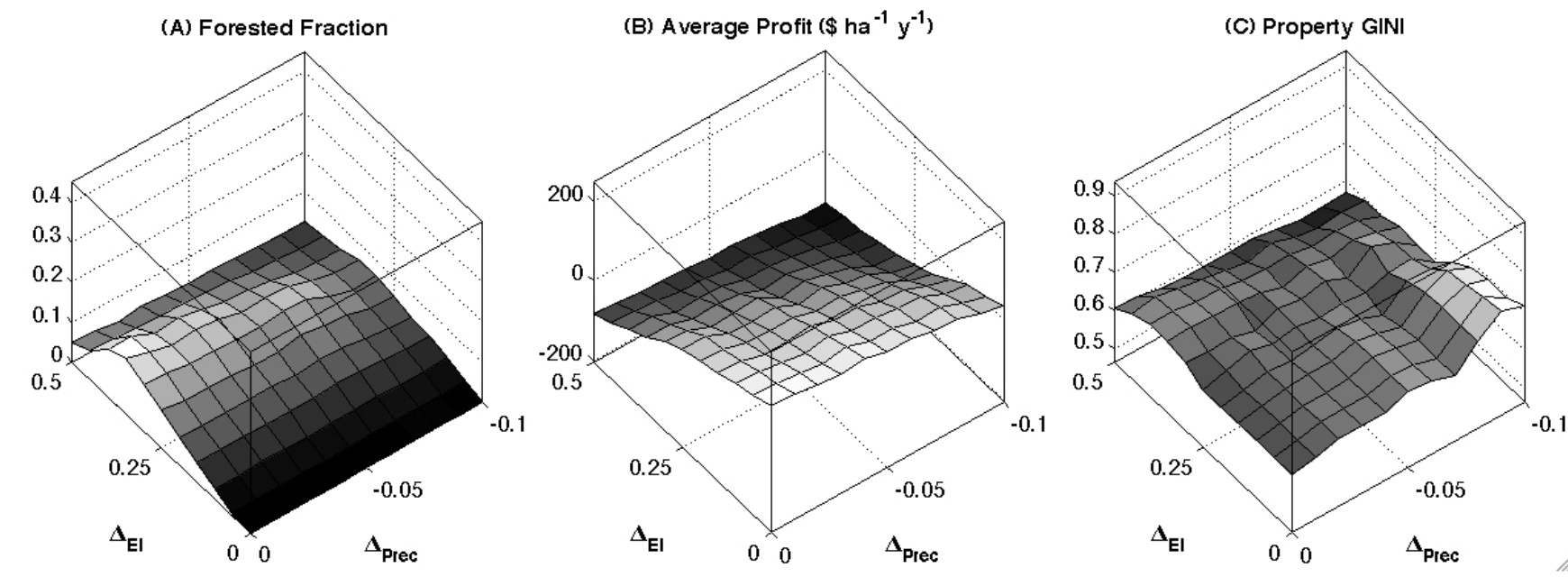

simply, for a policy to be effective, those it is meant to govern must be well informed. When size effect is high, meaning that strong network connections allow smaller ranches to behave much like larger ranches, the peak and drop in forested fraction is much less pronounced, i.e., small and large ranches alike are more able to turn a profit because their costs are lower, reflected in higher average profits per hectare.

In all network scenarios except for the high communication/high size effect scenario, both $\mathrm{D}_{\mathrm{EI}}$ and $\mathrm{D}_{\text {Prec }}$ act as drivers of land aggregation, measured as an increase in the property GINI, which provides some support for hypotheses $\mathrm{H} 1$ and $\mathrm{H} 3$ (see also Appendix 5). However, as was also the case for forested fraction, these relationships have a single peak, beyond which they decrease. The explanation is that although all ranches are impacted by stricter licensing or by drier weather, smaller ranches have less of a financial buffer once their basic needs and costs are met, and will be the first to need to sell cattle or land to make up for an expensive year. Larger ranches will be in a position to buy up this land and, initially at least, increases in $D_{E I}$ and $D_{\text {Prec }}$ lead to higher property GINI values.
However, as these stressors increase further, the profit margin for even larger properties disappears, leaving them unwilling or unable to purchase neighboring plots, and the property GINI peaks or drops off. If an incremental increase in either stressor makes smaller ranches more willing to sell faster than it makes larger ranches less willing to buy, it leads to a net increase in property GINI. In general, across the four rancher scenarios, the peak in property GINI is diminished when the two stressors are acting jointly, along the back edges of each of the surfaces. When size effect is high and all ranches have similar cost structure, any effect on land aggregation from $\mathrm{D}_{\mathrm{EI}}$ is minimal, which is to be expected because the smaller ranches share similar cost structure and mechanization to larger ranches in this scenario.

\section{Tiered environmental licensing}

The tiered environmental licensing option leads to several distinct outcomes relative to the untiered case (Fig. 4). The shapes of the curves remain similar, however, and these distinctions may be better viewed by looking at the difference in 
Fig. 4. Response surfaces for Policy Scenario 1 (tiered environmental licensing), Rancher Scenario 1 (low networking, low size effect) showing sensitivity to change in expected income $\Delta \mathrm{EI}$ and in precipitation $\triangle$ Prec. (A) Average forested fraction across the landscape; (B) Average profit per hectare of property per year; (C) Level of land aggregation measured by the property GINI coefficient. Response surfaces for Rancher Scenarios 1-4 are shown in Appendix 5, as are surfaces for the standard deviations across repetitions.
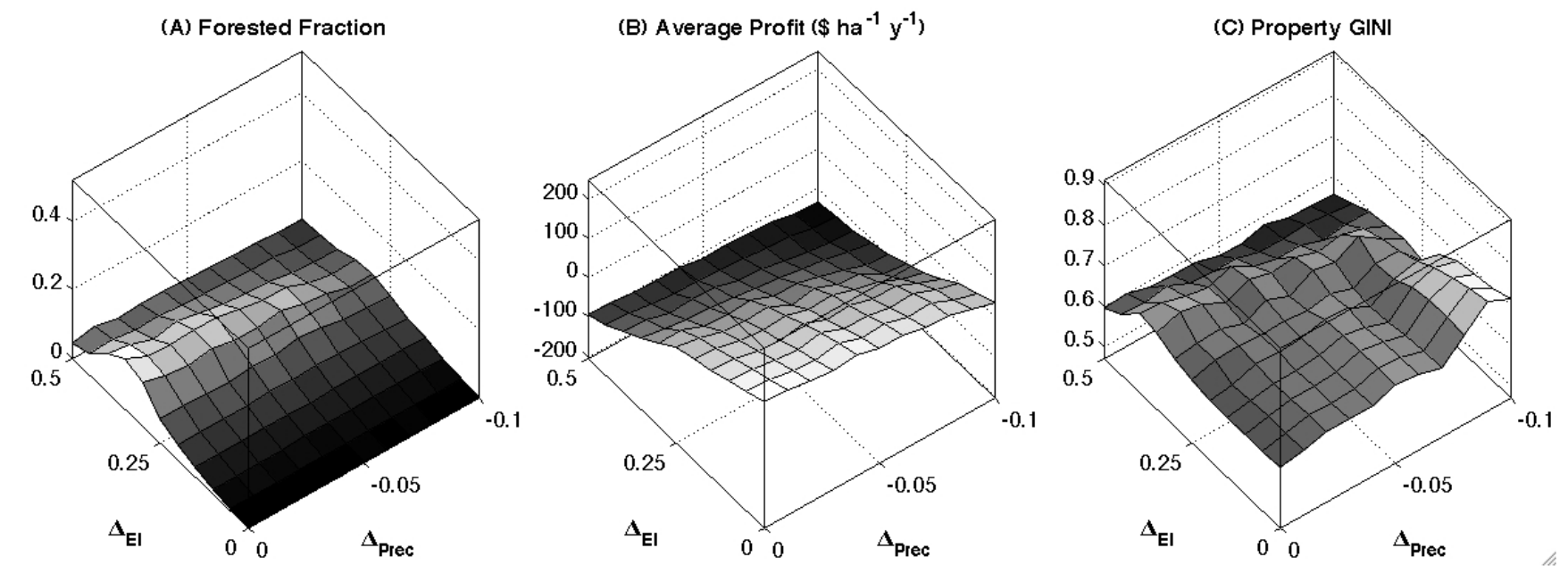

environmental, economic, and social outcomes between the two experiments (Fig. 5).

First, the forested fraction achieved is lower across all conditions relative to the untiered case, as would be expected. The effort to improve equity across ranch scale requires that smaller ranchers be held to a looser environmental standard, and the overall area of restored forest is reduced. The difference in average profits in the tiered case rises with $\mathrm{D}_{\mathrm{EI}}$, reflecting the relative ease that the lower environmental standard gives to the ranching landscape; this difference is less significant under conditions of lower precipitation, suggesting that the additional climate stress helps to equalize any differences between the two approaches.

The major result is that under a small range of conditions, the tiered approach to licensing does result in lower rates of land aggregation (as $D_{E I}$ initially increases from 0 ). This effect is most pronounced in the scenario where communication is high and size effect is low. In this scenario, ranchers are very well informed of the risk of being monitored and the costs those in their network are incurring, but gain little else through their network connections (Figure A5.3 in Appendix 5). Conversely, the effect is least pronounced in the case where both communication and size effect are high, i.e., where smaller ranches are able to act much like larger ranches and thus are less disproportionately affected by environmental licensing (Figure A5.3 in Appendix 5).

There is at best mixed support for hypothesis $\mathrm{H} 4$ however, since as conditions worsen $\left(\mathrm{D}_{\mathrm{EI}}\right.$ and $\mathrm{D}_{\text {Prec }}$ increase further) the tiered case appears to lead to higher levels of land aggregation than the nontiered case (the initial dips in Figure 5 in property GINI as $\mathrm{D}_{\mathrm{EI}}$ increased from 0 now rise). The implication is that, rather than eliminating the problem of land aggregation, the tiered approach simply shifts the domain in which $\mathrm{D}_{\mathrm{EI}}$ and $\mathrm{D}_{\text {Prec }}$ act as drivers of land aggregation farther out. That is, under moderate climate or policy stress, the tiered approach can ameliorate some of the pressure on small properties, but if the stressors intensify, the same issue may return. This is even clearer when looking at the relative standard deviations across replications (Figures A5.5, A5.6 in Appendix 5). As ranches begin to fail, the variance in profitability across the landscape increases, i.e., some farms are doing well 
Fig. 5. Response surfaces for the differences between Policy Scenarios 1 and 2, given as (Outcome in Policy 2 - Outcome in Policy 1), for Rancher Scenario 1 (low networking, low size effect). (A) Average forested fraction across the landscape; (B) Average profit per hectare of property per year; (C) Level of land aggregation measured by the property GINI coefficient. Response surfaces for Rancher Scenarios 1-4 are shown in Appendix 5.
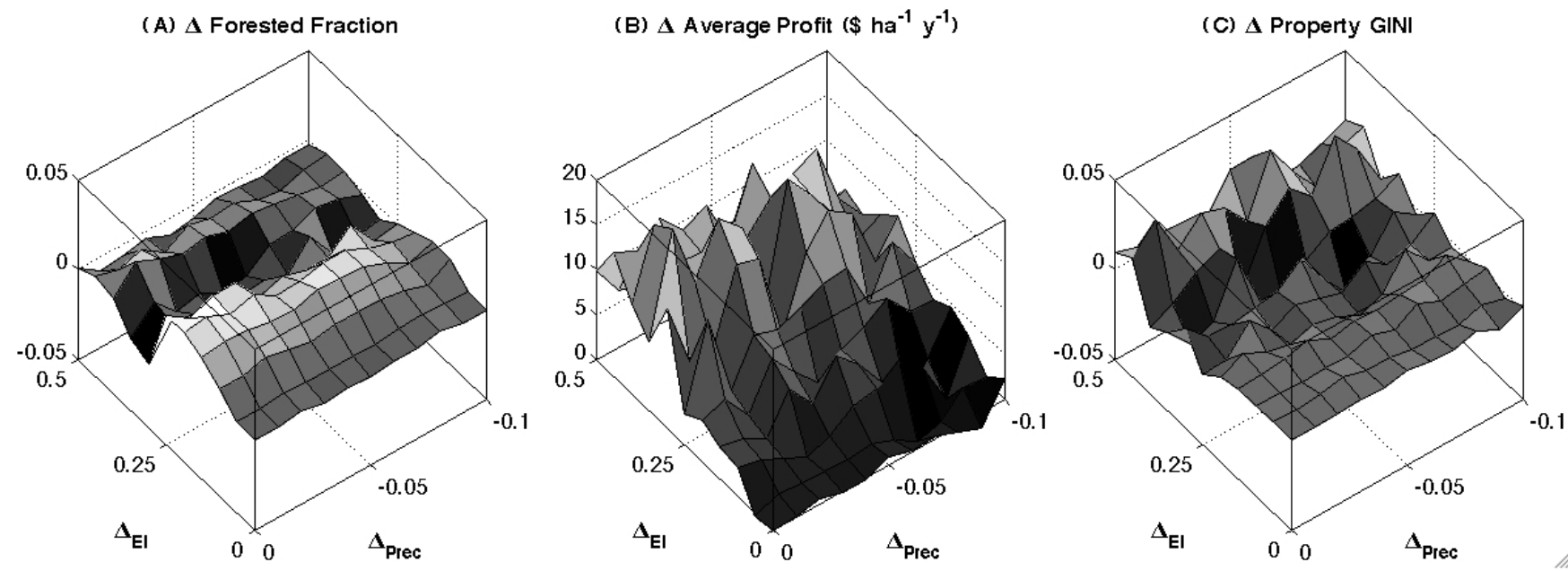

while others are failing, and then falls off as conditions worsen, i.e., all farms are failing. The sharp ridge on the surface for profitability in Figures A5.5 and A5.6 in Appendix 5 marks the threshold, as a function of both climate and licensing stressors, where ranches begin to fail. Comparing the two figures, these ridges move farther out from the origin $\left(D_{E I}=D_{\text {Prec }}=0\right)$ in the tiered case, suggesting a boundary shift or distortion rather than a problem solution.

\section{Another approach to achieving a socially equitable outcome}

The tiered licensing proposal is unpopular among those who do not stand to benefit. Hence, it is worthwhile to look for other means of achieving more equitable results under licensing. Rather than creating explicit tiers that may or may not map well onto functional groups of ranchers it should be possible to design a monitoring and enforcement scheme that implicitly lessens the burden that licensing places on smaller ranchers.

The monitoring and enforcement process in this model has two parts: (1) monitoring of land use on individual properties and allocation or stripping of licenses, and (2) verification of licenses at the point of sale of cattle, such as at a slaughterhouse. In the model, properties are selected for monitoring based on size; a fraction of the cells in the grid is selected randomly, and the properties to which they belong are selected. In this way, larger properties are at a higher risk of being caught. This is a reasonable representation, because any real agency with limited, and perhaps minimal, resources would likely choose to target a smaller number of relatively large targets over a large number of smaller targets. However, all ranchers in the simulation forfeit the same proportion of their revenue $\mathrm{D}_{\mathrm{EI}}$ when they lose their licenses. If $\mathrm{D}_{\mathrm{EI}}$ is interpreted as a measure of the difficulty of unloading cattle, this too is reasonable, since all truckloads of cattle present themselves to slaughterhouses in much the same way, regardless of how large the property from which they come.

The agency tasked with monitoring and enforcement must choose how to divide effort between the two parts of the process described above to maximize some objective function. The monitoring of individual properties would likely involve the use of real-time satellite imagery of the 
Fig. 6. Response surfaces for Policy Scenario 3 (nontiered environmental licensing), Rancher Scenario 1 (low networking, low size effect) showing sensitivity to change in expected income $\Delta \mathrm{EI}$ and in probability of monitoring $\mathrm{p}_{\text {mon }}$. (A) Average forested fraction across the landscape; (B) Average profit per hectare of property per year; (C) Level of land aggregation measured by the property GINI coefficient. Response surfaces for Rancher Scenarios 1-4 are shown in Appendix 5, as are surfaces for the standard deviations across repetitions.
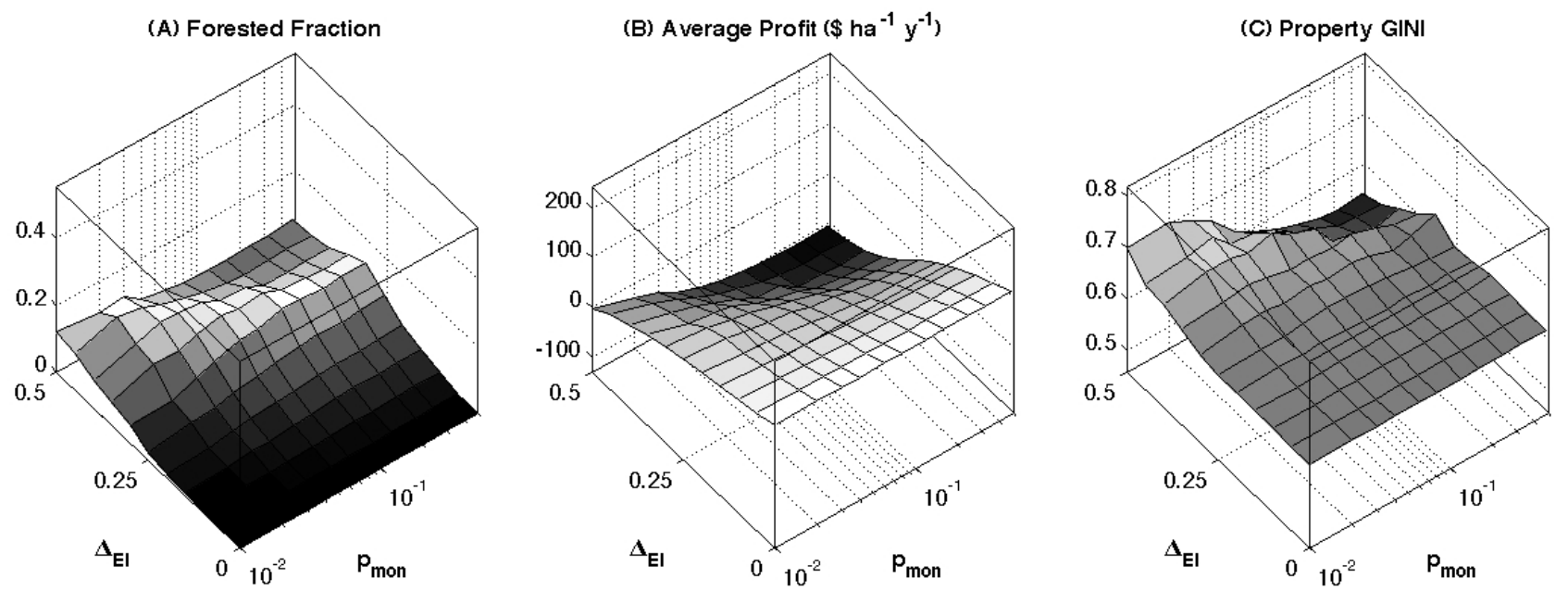

property in question, as well as a site visit and consultation with the property owner regarding his or her management plan. The verification of licenses at the point of sale would require the stationing of an agent at a slaughterhouse or the provision of incentives to the slaughterhouse to require licenses as a part of the sale. Considering these processes for monitoring and enforcement together, the implication is that if the objective is to make equitable the burden placed by licensing on ranches, in the modeled system, more effort should be allocated to site monitoring, and less to point-ofsale verification of licenses.

This implication plays out in the experimental results. Figure 6 shows a set of outcome surfaces generated by varying both $\mathrm{D}_{\mathrm{EI}}$ and $\mathrm{p}_{\mathrm{mon}}$. Forested fraction increases along both $\mathrm{D}_{\mathrm{EI}}$ and $\mathrm{p}_{\text {mon }}$ dimensions until it peaks, so that curves of equal forested fraction, 'isoforest' curves, can be drawn that show how monitoring effort $\left(\mathrm{p}_{\text {mon }}\right)$ can substitute for control over market access $\left(\mathrm{D}_{\mathrm{EI}}\right)$ to give equivalent forest outcomes. Per-hectare profit strictly decreases along both $\mathrm{D}_{\mathrm{EI}}$ and $\mathrm{p}_{\text {mon }}$, so that similar isoprofit curves can be drawn. In general, the isoforest and isoprofit curves map closely onto each other, which is to be expected; similar areas in forest should indicate similar areas in pasture, and thus similar levels of revenue generated on average across the landscape. However, the same relationship does not hold for the property GINI.

With the notable exception of the high communication, high size effect case, the property GINI is generally higher when $\mathrm{D}_{\mathrm{EI}}$ is high and $\mathrm{p}_{\text {mon }}$ is low, and downward sloping as $\mathrm{D}_{\mathrm{EI}}$ decreases and $\mathrm{p}_{\text {mon }}$ increases (Fig. D.4). Thus, moving along the isoprofit and isoforest curves associated with the peak forested fraction from higher $\mathrm{D}_{\mathrm{EI}}$ toward higher $\mathrm{p}_{\text {mon }}$, the property GINI decreases, implying lower rates of land aggregation and a social outcome that is more favorable for smaller ranches (Fig. 7). This effect is most pronounced in the low communication, low size effect case; where ranchers on small properties are the least informed of the risks they face and where their costs are considerably higher than those for larger properties, they have the most to gain by shifts in policy that place more burden on larger properties.

Because site monitoring is likely to be the more resource intensive component of the monitoring and 
Fig. 7. Contour curves for the Low Network, Low Size Effect case shown in Figure 6; darker curves indicate lower values. A vector (dashed line) drawn along the ridge of nearly constant peak forested fraction corresponds closely with an isoprofit contour, but also with a nearly strictly decreasing property GINI.
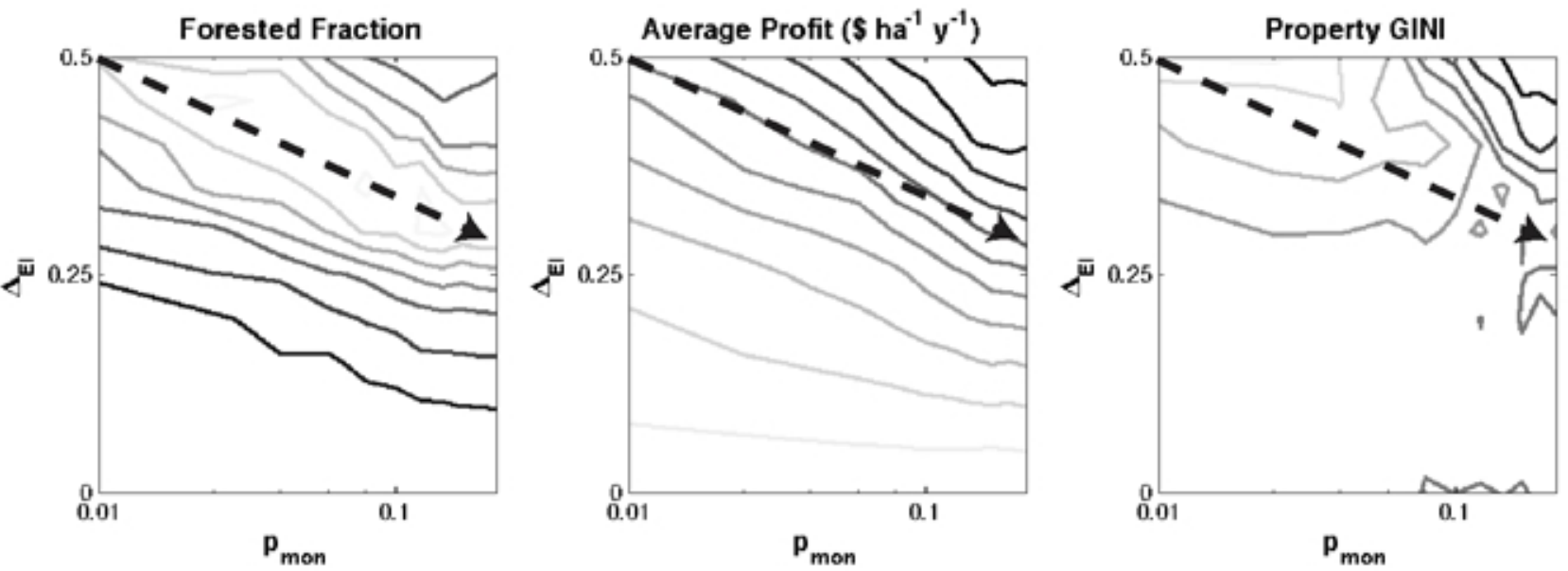

enforcement process, it is important that this social equity benefit be emphasized. Figure 7 shows that site monitoring and point-of-sale enforcement can substitute for one another to preserve forest cover and average profit levels, but that site monitoring will not simultaneously preserve the capacity for smaller ranches to produce.

\section{SO WHAT? LINKING MODEL RESULTS BACK TO REALITY}

A key process in making insights derived from modeling results useful to real-world situations is to step back through the set of simplifying assumptions upon which the model is built and understand how these insights change as the assumptions are relaxed. In this model, a number of simplifying assumptions were made regarding land market structure, the monitoring and enforcement of fines, and land-use decisions, and it is important now to discuss how the more complex, real-world versions of these processes might modify the study results.

First, only parcels offered by ranches in deficit entered the land auction in the model. This is certainly a major component of land that gets sold in real ranching landscapes, but is incomplete; successful ranchers may also be aggressively attempting to buy up local properties in an effort to grow. This mechanism is excluded here to avoid introducing further assumptions about how ranchers choose to invest their money; the impact of excluding this mechanism is likely to be a more conservative estimate of land aggregation, since only some of the means through which successful ranchers can buy up neighboring land are included.

Another important simplification in the model is that there are no wholly unexpected costs borne by the ranchers. In reality, the failure of equipment as well as illnesses and injuries among family members are unpredictable shocks and can drive the need to sell off cattle or land in a pinch. It is reasonable to assume that the risk of injury or illness is uniform across the population, if not higher among poorer ranchers, and that richer ranchers will be better prepared to weather these shocks. Again, this simplifying assumption likely leads to a more conservative estimate of the rate of land aggregation.

The mechanism through which changes in climate influence production in this model is simple: a decline in precipitation results in decreased grass 
growth, which in turn increases the cost to the rancher to supplement cattle diets during dry periods. Although such a relationship has a basis in the literature (Svoray et al. 2008, Hirota et al. 2010), it is certainly not the only way climate might affect the growth of grass or other crops. In reality, shifts in the mean levels as well as the temporal distribution of precipitation and temperature may have positive or negative effects on grass growth depending on whether they pull conditions toward or away from what is optimal for the plant. Thus, it is worth interpreting the climate effects more loosely, as in, to the extent that changes in temperature or precipitation inhibit grass growth, they may act as drivers of land aggregation in the Rondonian ranching landscape. Integrating more sophisticated relationships between vegetation growth and climate into models focused on social processes, like this one, is an important direction for future work.

It is worth noting as well that, particularly on smaller farms in Rondônia, land use is diversified away from exclusive cattle production and into crop production, such as coffee or beans, for consumption and markets. Diversification is commonly cited in the development literature as a coping strategy to climate variability. However, in this particular system where cattle production and markets are so well developed, it is more difficult to argue that production of coffee, for example, alongside cattle helps reduce climate-related vulnerability. It is more likely that when climate impacts are significant enough to affect cattle health, other crops would be more significantly affected, so that impacts on small farmers with production more diversified than the cattle producers in this model would be more severe.

The other major assumptions that steer model results relate to monitoring and enforcement. It is assumed in this model that all ranchers will have the same difficulty marketing their product without a license, and thus the same $\mathrm{D}_{\mathrm{EI}}$ is applied to all ranchers. In reality, it would not be unreasonable that larger, more powerful ranches would be better positioned to circumvent rules and obtain good prices than might smaller ranches; this is another effect that might tip outcomes in favor of larger ranches.

In sum, this first set of assumptions in this model provide what is likely a conservative assessment of the role that environmental licensing in Rondônia could play, in concert with expected climate stresses, in driving rates of land aggregation, given some nontrivial capacity for monitoring and enforcement of the licensing scheme. Relaxing these assumptions, one could expect more severe impacts on smaller property holders in the real system than demonstrated in the model, and further aggregation of land holdings. In terms of the study hypotheses, this means a stronger case for the findings for $\mathrm{H} 1, \mathrm{H} 3$, and $\mathrm{H} 4$ (Table 3).

The last major assumption of the model is that effective monitoring and enforcement occurs at all. This is a key assumption because strong evidence exists to suggest that little enforcement of policy does take place. IBAMA, the federal environmental protection agency, recently estimated that they collected only a small fraction (less than $5 \%$ ) of the fines that they levied (Hall 2008). In the sample, only a small fraction (less than 20\%) of properties reported even having their properties visited by members of a public agency for the purposes of observing environmental quality. The process of visiting sites also requires an accurate and current land registry; although registration for LAPRO will help facilitate this, a complete registry should not be taken as given. It is clear that under such conditions the real impact that environmental licensing may have is trivial to evaluate, i.e., little will happen; reports from licensing schemes elsewhere in Amazônia do not yet suggest much success elsewhere in the region (Lima et al. 2005). This reality means that the study findings with respect to $\mathrm{H} 2$ must be interpreted with caution (Table 3). The model developed in this study is not the appropriate tool to investigate why such monitoring and enforcement does not occur, nor how it might be encouraged. The value of this study is in highlighting the benefits that can arise from effective implementation of environmental licensing, and in examining how the social impacts of licensing can be managed, under the assumption of some real capacity for effective implementation.

This study contributes to what is still a small body of agent-based models tied to empirical data (Berger and Schreinemachers 2006), and an even smaller body that examines structural change in farms (Zimmermann et al. 2009), by tying rancher decision making in with climate and representing the set of conditions particular to the Amazonian frontier and postfrontier. The Rondônia case is just one of many where land-use practices established through colonization or resource exploitation are in 
Table 3. Evidence summary for hypotheses.

\begin{tabular}{lll}
\hline \hline & Hypothesis & Support \\
\hline H1: & $\begin{array}{l}\text { Decreases in precipitation will drive increased rates of land } \\
\text { aggregation }\end{array}$ & Strong, given real constraints on smaller properties \\
H2: & $\begin{array}{l}\text { Environmental licensing will lead to better environmental } \\
\text { outcomes on properties currently lacking significant forest } \\
\text { cover }\end{array}$ & $\begin{array}{l}\text { Strong, if licensing implemented effectively; weak, } \\
\text { otherwise }\end{array}$ \\
H3: & $\begin{array}{l}\text { Reduced access to markets through environmental licensing } \\
\text { will drive increased rates of land aggregation }\end{array}$ & $\begin{array}{l}\text { Strong, if licensing implemented effectively, given } \\
\text { real constraints on smaller properties }\end{array}$ \\
H4: & $\begin{array}{l}\text { Reduced licensing requirements for small properties will lead } \\
\text { to lower rates of land aggregation }\end{array}$ & $\begin{array}{l}\text { Weak to fair, depending on how licensing is } \\
\text { implemented }\end{array}$ \\
\hline
\end{tabular}

conflict with present-day goals for environmental preservation, but are depended upon to preserve livelihoods. Beyond POLONOROESTE, through which much of Rondônia's settlement was funded, the World Bank funded projects in the 1980s in Indonesia, Asia, and the Congo that included as goals the transmigration of peoples and the liquidation of forest assets as a means to economic development (Fearnside 1997, Ekoko 2000, Rachman et al. 2009). As long as legacies of these projects remain, they will continue to present conflict among environmental, economic, and social goals. The results presented in this study should offer some hope that these dissonant goals may be harmonized, and that tools like agent-based models allow explicit study of the tensions among them.

Responses to this article can be read online at: http://www.ecologyandsociety.org/vol16/iss 1/art31/ responses/

\section{Acknowledgments:}

This study was funded by grants from the Graham Environmental Sustainability Institute and the Rackham Graduate School, both at the University of Michigan. The questionnaire developed for this study drew from material previously developed by the ACT Institute at Indiana University. Initial support in project planning and development was provided by Tatiane Checchia and Paulo Schröder at the Amazônian Protection System (SIPAM). Logistic support in the administration of questionnaires was provided by the agency for technical assistance and rural extension for Rondônia, EMATER-RO. Finally, the author is grateful for assistance in project coordination from Dr. Margarida Marchetto of the Federal University of Rondonia (UNIR) and for the hard work of the research team - Thiago Emanuel Figueiredo Possmoser Nascimento, Ingrid Alexandrina Martins Veronez, Emerson Andrade de Souza, Mônica Chagas Cerquiera, João Paulo Papaleo Costa Moreira, Carina Stre Holanda, and Leonardo Rosa Andrade - from the Department of Environmental Engineering at UNIR Ji-Paraná.

\section{LITERATURE CITED}

Aldrich, S., R. Walker, E. Arima, M. Caldas, J. Browder, and S. Perz. 2006. Land-cover and landuse change in the Brazilian Amazon: smallholders, ranchers, and frontier stratification. Economic Geography 82:265.

ambientebrasil. 2010. Licenciamento Ambiental em Propriedade Rural na Amazônia. [online] URL: http://www.ambientebrasil.com.br/composer.php3? base=./gestao/index.html\&conteudo=./gestao/programas/ licenciamento amazonia.html. 
Berger, T. 2001. Agent-based spatial models applied to agriculture: a simulation tool for technology diffusion, resource use changes and policy analysis. Agricultural Economics 25:245-260.

Berger, T., and P. Schreinemachers. 2006. Creating agents and landscapes for multiagent systems from random samples. Ecology and Society 11(2): 19. [online] URL: http://www.ecologyandsociety.org/vol11/ iss2/art19/.

Caviglia-Harris, J. L. 2004. Household production and forest clearing: the role of farming in the development of the Amazon. Environment and Development Economics 9:181-202.

D'Antona, A. O., L. K. VanWey, and C. M. Hayashi. 2006. Property size and land cover change in the Brazilian amazon. Population and Environment 27:373-396.

de Jesus, A. 2009. Altera e acresce dispositivos à Lei $n^{\circ} 4.771$, de 15 de setembro de 1965, Código Florestal Brasileiro. PL 5020/2009 Brasília, Brazil. [online] URL: http://www.camara.gov.br/sileg/Pro p Detalhe.asp?id=429594.

Ekoko, F. 2000. Balancing politics, economics and conservation: the case of the Cameroon Forestry Law reform. Development and Change 31:131-154.

Ellis, F. 1993. Peasant economics: farm households and agrarian development. Cambridge University Press, Cambridge, UK.

Ewers, R. M., and W. F. Laurance. 2006. Scaledependent patterns of deforestation in the Brazilian Amazon. Environmental Conservation 33:203-211.

Faminow, M. D. 1997. Spatial economics of local demand for cattle products in Amazon development. Agriculture Ecosystems \& Environment 62:1-11.

Fearnside, P. M. 1997. Transmigration in Indonesia: lessons from its environmental and social impacts. Environmental Management 21:553-570.

Fearnside, P. M. 2001. Land-tenure issues as factors in environmental destruction in Brazilian Amazonia: the case of Southern Para. World Development 29:1361-1372.
Fearnside, P. M. 2007. Brazil's Cuiabá-Santarém (BR-163) Highway: the environmental cost of paving a soybean corridor through the Amazon. Environmental Management 39:601-614.

Hall, A. 2008. Better RED than dead: paying the people for environmental services in Amazonia. Philosophical Transactions of the Royal Society BBiological Sciences 363:1925-1932.

Happe, K., A. Balmann, K. Kellermann, and C. Sahrbacher. 2008. Does structure matter? The impact of switching the agricultural policy regime on farm structures. Journal of Economic Behavior and Organization 67(2):431-444.

Happe, K., K. Kellermann, and A. Balmann. 2006. Agent-based analysis of agricultural policies: an illustration of the agricultural policy simulator AgriPoliS, its adaptation, and behavior. Ecology and Society 11(1): 49. [online] URL: http://www.e cologyandsociety.org/vol11/iss1/art49/.

Happe, K., H. Schnicke, C. Sahrbacher, and K. Kellermann. 2009. Will they stay or will they go? Simulating the dynamics of single-holder farms in a dualistic farm structure in Slovakia. Canadian Journal of Agricultural Economics-Revue canadienne d'agroeconomie 57:497-511.

Hecht, S., and A. Cockburn. 1989. The fate of the forest: developers, destroyers, and defenders of the Amazon. Verso, London, UK.

Hirota, M., C. Nobre, M. D. Oyama, and M. M. C. Bustamante. 2010. The climatic sensitivity of the forest, savanna and forest-savanna transition in tropical South America. New Phytologist 187:707-719.

Instituto Brasileiro de Geografia e Estatística (IBGE). 1996. Censo Agropecuário de 1995-1996. Instituto Brasileiro de Geografia e Estatística, Brasília, Brazil. [online] URL: http://www.ibge.gov. br/home/estatistica/economia/agropecuaria/ censoagro/1995 1996/default.shtm.

Instituto Brasileiro de Geografia e Estatística (IBGE). 2006. Censo Agropecuário de 2005-2006. Instituto Brasileiro de Geografia e Estatística, Brasília, Brazil. [online] URL: http://www.ibge.gov. br/home/estatistica/economia/agropecuaria/ censoagro/2006/default.shtm. 
Lima, A., A. Rolla, M. Wathely, C. C. Augusto, and R. A. Alves. 2005. Mato Grosso, Amazônia (i) Legal: Desmatamentos de florestas em propriedades rurais integradas ao Sistema de Licenciamento Ambiental Rural entre 2001 e 2004. Instituto Socioambiental, Brasília, Brazil.

Magrin, G., C. Gay García, D. Cruz Choque, J. C. Giménez, A. R. Moreno, G. J. Nagy, C. Nobre, and A. Villamizar. 2007. Latin America. Chapter 13 in M. L. Parry, O. F. Canziani, J. P. Palutikof, P. J. van der Linden and C. E. Hanson, editors. Climate change 2007: impacts, adaptation and vulnerability. Contribution of Working Group II to the Fourth Assessment Report of the Intergovernmental Panel on Climate Change. Cambridge University Press, Cambridge, UK.

Parker, D. C., S. M. Manson, M. A. Janssen, M. J. Hoffmann, and P. Deadman. 2003. Multi-agent systems for the simulation of land-use and landcover change: a review. Annals of the Association of American Geographers 93:314-337.

Pfaff, A. S. P. 1999. What drives deforestation in the Brazilian Amazon? Evidence from satellite and socioeconomic data. Journal of Environmental Economics and Management 37:26-43.

Pfaff, A., J. Robalino, R. Walker, S. Aldrich, M. Caldas, E. Reis, S. Perz, C. Bohrer, E. Arima, W. Laurance, and K. Kirby. 2007. Roads and deforestation in the Brazilian Amazon. Journal of Regional Science 47:109-123.

Rachman, N. F., L. A. Savitri, and M. Shohibuddin. 2009. Questioning pathways out of poverty: Indonesia as an illustrative case for the World Bank's transforming countries. Journal of Peasant Studies 36:621-627.

Secretaria de Estado do Desenvolvimento Ambiental (SEDAM-RO). 2008. Manual Operacional Para a Licença Ambiental em Propriedade Rural no Estado de Rondônia. Secretaria de Estado do Desenvolvimento Ambiental, Porto Velho, Rondônia, Brazil.

Simon, M. F., and F. L. Garagorry. 2005. The expansion of agriculture in the Brazilian Amazon. Environmental Conservation 32:203-212.
Soares, B., A. Alencar, D. Nepstad, G. Cerqueira, M. D. V. Diaz, S. Rivero, L. Solorzano, and E. Voll. 2004. Simulating the response of land-cover changes to road paving and governance along a major Amazon highway: the Santarem-Cuiaba corridor. Global Change Biology 10:745-764.

Svoray, T., R. Shafran-Nathan, Z. Henkin, and A. Perevolotsky. 2008. Spatially and temporally explicit modeling of conditions for primary production of annuals in dry environments. Ecological Modelling 218:339-353.

Zimmermann, A., T. Heckelei, and I. P. Dominguez. 2009. Modelling farm structural change for integrated ex-ante assessment: review of methods and determinants. Environmental Science \& Policy 12:601-618. 


\section{Appendix 1}

\section{Agent-based Model Description}

The following sections present the model used in this study following the ODD protocol (Grimm et al. 2006).

\section{PURPOSE}

This model has been designed to investigate the impact of different incentive structures for the maintenance of forest cover on rural properties on overall forest cover, ranchland profitability, and social equity among ranchers with different endowments.

As a note, this model borrows architecture from an earlier model designed to investigate the impact of different policies on water quality, and retains the hydrological model built therein, though this sub-model is only used here to estimate evapotranspiration from pasture grass.

\section{STATE VARIABLES AND SCALES}

The modeled environment consists of a two-dimensional grid space representing a ranching landscape. Each grid cell has land distributed into three land uses - forest, pasture, and degraded pasture - and a stock of standing grass biomass growing on the fraction of land in pasture. The modeling space includes a set of agents or 'Ranchers', each of which 'occupies' a subset of the cells in the landscape. This subset of cells comprises the 'ranch' of a given agent; all grid cells are allocated to be part of one ranch.

The ranchers each maintain a stock of cattle, allocated across the pastured fraction of the grid cells in their ranch. They have a stock of cash received from the sale of cattle and used to maintain and change land, as well as supplement cattle diets, pay household costs, and purchase new land. They may possess environmental licenses, which give them access to better market prices for their cattle. They also maintain network connections of varying strength with the other ranchers in the landscape, and observe from other ranchers in the network how often they are monitored with respect to licensing requirements; these connections also serve as proxies for capital and labor support, and can allow farmers to operate at effectively higher scales (as though they were sharing capital such as tractors and working as teams). 
Processes in the modeled environment occur at two distinct time scales. Physical and biological processes such as rainfall, grass growth, and pasture degradation are resolved in a daily time step; agent decision processes such as the stocking and culling of cattle, modification of land use, and sale of land are resolved at a decision interval, which can be defined by the user to be every month, every 3 months, each year, etc. (In the present study, the decision interval is resolved at 1 year intervals).

\section{PROCESS OVERVIEW AND SCHEDULING}

(Daily Time-step)

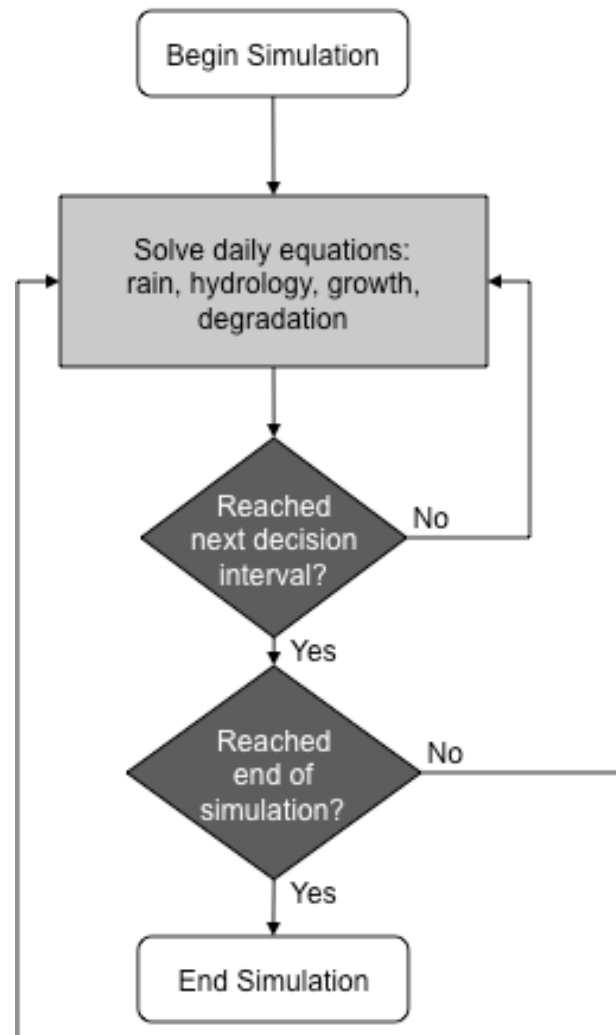

(Decision Interval)

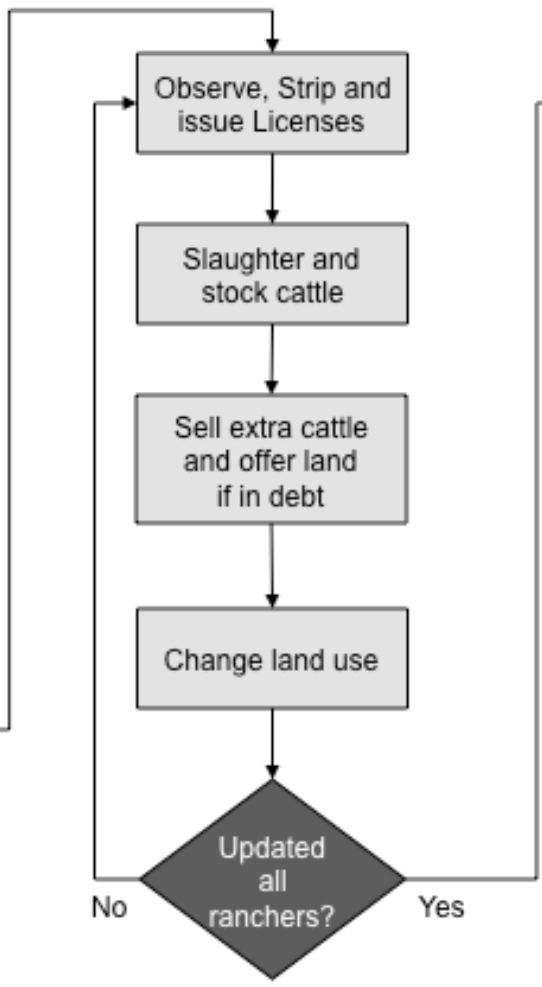

(Land Auction)

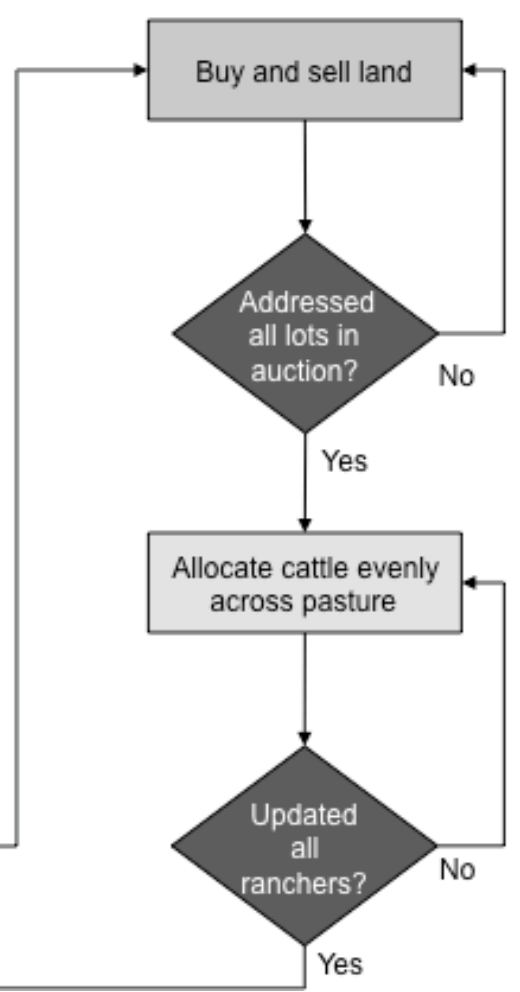

Figure A1.1: Simulation Flow Chart. Processes completed in each daily time-step are shown on the left. Processes occurring at each decision interval (which may be defined to occur at intervals of 1-month, 6month, 1-year, etc.) are shown in the middle column. Processes tied to the land auction and redistribution of land and cattle (which occurs at the end of each decision interval) are indicated in the right column.

\section{DESIGN CONCEPTS}

\subsection{Emergence}


The aggregate, landscape scale patterns of forest cover, profitability, and social equity (see Observation below for measures) emerge out of the decisions of the ranchers, which in turn are informed by their observations of their own properties and communication with other ranchers.

\subsection{Adaptation}

Ranchers adjust their expectation of being visited by a monitor based on their observations of other ranchers in the network being monitored, and use this expectation to decide how closely to the requirements of the license they need to remain.

\subsection{Fitness}

The rancher's cash stock, cattle, and land become measures of fitness in this model; ranchers without sufficient revenue must sell off their cattle and eventually their land to stay afloat. Unfit ranchers are those who are unable to maintain their wealth and sell off remaining land to leave the landscape.

\subsection{Prediction}

Ranchers have the expectation that future likelihoods of monitoring will reflect the previous history of monitoring, and use this historical memory as a predictor of monitoring likelihood.

\subsection{Sensing}

Ranchers are aware of what is occurring on their property - how much cattle they have, how well the grass is growing, how much it is raining, and how their land is distributed into land-use classes - and learn of monitoring visits on other farms through interactions with other ranchers in the network.

\subsection{Interaction}

Ranchers interact to exchange information on monitoring visits. Also, the strength of network connections a rancher has with others in the network serves as a proxy for the capacity to share capital equipment and labor, and thus can allow smaller farms to behave more like larger farms (see Ranching Network in Sub-models section)

\subsection{Stochasticity}

Parameters for grass capacity and growth rate for each cell are drawn from random distributions. Daily rainfall is also drawn from a random distribution. Interactions among particular ranchers occur at each decision interval stochastically based on the strength of the connection between them (which in turn is determined randomly). Additionally, the selection of sites to monitor in a given period, as well as the decision to strip farmers of their licenses, involve numbers drawn from random distributions. 
In all instances, these distributions are used to substitute for complex causal processes (leading to rainfall, interactions, and discovery of violations, etc.) that are beyond the scope of the current model to reproduce.

\subsection{Collectives}

Ranchers are all part of a network and share links of varying strength to all other ranchers in the system. These links shape the likelihood that monitoring events happening to one rancher will be communicated to the other, and as well, the aggregate sum of link strengths one rancher has to other ranchers becomes a proxy for the ability to share resources with other ranchers and act as an effectively larger farm.

\subsection{Observation}

Aggregate properties of the ranching system are observed through an environmental variable (the forested fraction of the landscape), an economic variable (the average profitability per hectare of ranching across the landscape) and a social variable (the property GINI, a measure of how evenly land resources, on an area basis, are distributed among the ranchers present at the beginning of the simulation).

\section{INITIALIZATION}

Grid cells in the space are initialized as completely covered in pasture, with a randomly drawn growth rate and per-hectare grass capacity. Specifically, the variability $\delta$ is used in the initial model setup to define the land characteristics $G^{*}{ }_{\max }$, and $\mathrm{k}_{\text {grass }}$ for each grid cell, such that:

$$
\begin{gathered}
G_{\text {max }}^{*}=G_{\text {max,base }}^{*}(1 \pm(1+U[-\delta, \delta])) \\
k_{\text {grass }}=k_{\text {grass,base }}(1 \pm(1+U[-\delta, \delta]))
\end{gathered}
$$

where $\mathrm{U}$ is a uniform random distribution.

Ranch agents are allocated land based on the distribution observed in the sample collected in the current study (see main article), and given initial cash endowment to begin stocking their land, paying expenses, and maintaining pasture. Information links among ranchers are drawn randomly. The complete table of model parameters is included as Appendix 2 to this study.

\section{Input}

See the description of experiments in the main article.

\section{SUB-MODELS}

The following sections outline the following sub-models: climate, hydrology, cattle growth, grass growth, and pasture degradation, which are resolved at a daily time-step using a RungeKutta 4-step algorithm; and the set of processes involving ranchers at the decision-interval scale, 
including land-use change, cattle stocking, land sale, calculation of costs, environmental licensing, and the ranching network connections.

\subsection{Climate}

In the model, daily precipitation for day $j$ is drawn from an exponential distribution of mean $\lambda_{k}$, where $k$ is the month of the year:

$$
\text { Precipitation }_{j}(m m)=X \sim \operatorname{Exp}\left[\left(1+\Delta_{\text {Prec }}\right) \lambda_{k}\right]
$$

That is, all precipitation values for days $j$ that fall in the same month $k$ will be drawn from the same distribution. Integer values for each month have been chosen that preserve rainy-dry season structure and an average rainfall for the region of about 1800-2200 $\mathrm{mm}$ per year, consistent with actual field measurements for Rondônia (von Randow et al. 2004). The term $\left(1+\Delta_{\text {Prec }}\right)$ scales the annual precipitation up or down by the factor $\Delta_{\text {Prec }}$.

\subsection{Hydrology}

The model includes a full hydrological sub-model that partitions incoming rainfall into overland flow, groundwater runoff, and evapotranspiration. This submodel was designed to investigate rates of overland flow and soil erosion, though these outcomes are not of interest to the current study. The full hydrological model is introduced in this appendix however, as the evapotranspiration outcome is used to calculate grass growth.

A component of the precipitation is taken up on the leaf surface and lost as evapotranspiration, while the remaining precipitation reaches the ground as throughfall (Figure A1.2). Assuming a mean duration $l_{\text {event }}$ hours for rainfall events, there may be some component of rainfall in intense storms that exceeds the infiltration capacity for the soil (though in the present set of experiments there was no such infiltration excess).

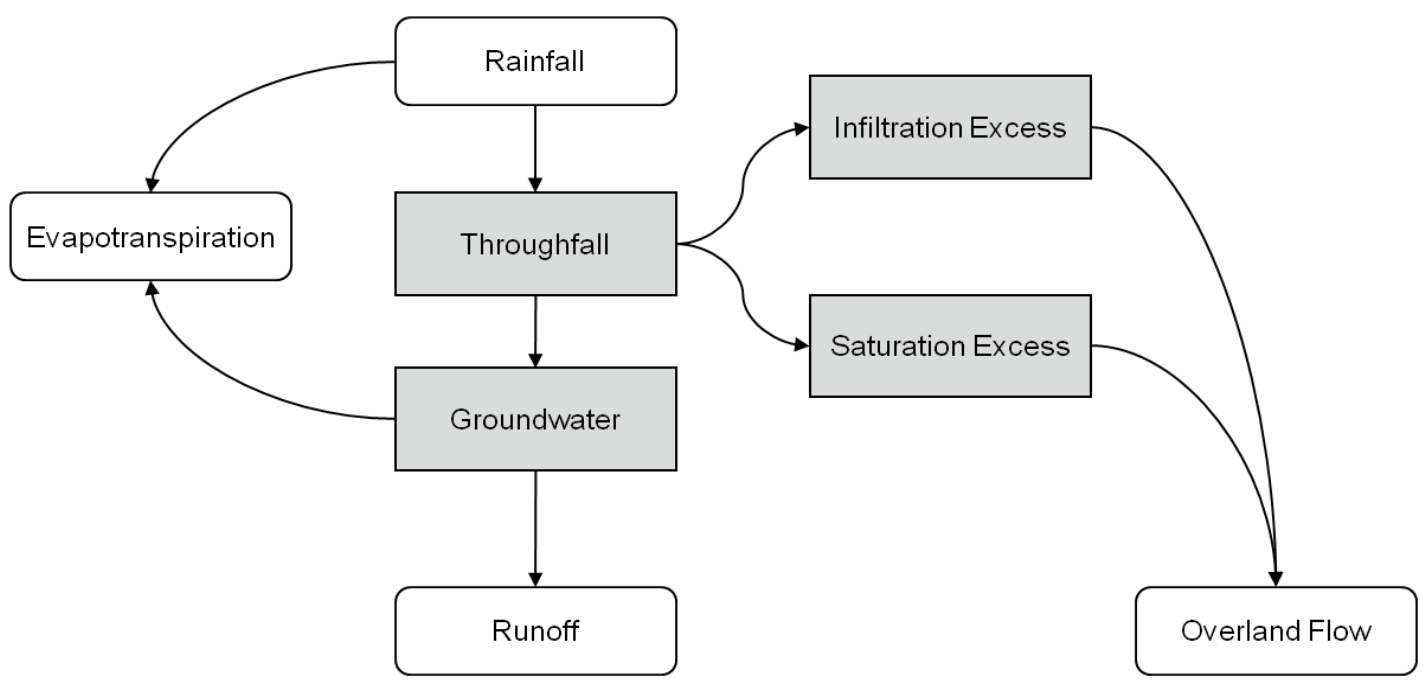

Figure A1.2: Hydrological submodel scheme 
Some component of the throughfall flows over the surface as saturation excess. Together, infiltration and saturation excess make up the total overland flow in the system. The remaining throughfall enters the ground, and some component is taken up by plant roots; the remainder exits the system as stream runoff. This system is represented mathematically by:

$$
\begin{aligned}
& \text { Throughf all }=\left(1-f_{E V, \text { Leaf }}\right) \text { Precipitation }- \text { Inf iltExcess-SatExcess } \\
& \text { Groundwater }=\text { Throughf all } \\
& -\max \left(\text { Groundwater, } E V_{\text {pot }}-f_{E V, \text { Leaf }} \cdot\right. \text { Precipitation) } \\
& - \text { Runoff } \\
& \begin{array}{c}
\text { Runof } f=\frac{\text { Head }}{L} \cdot K_{\text {Sat }} \\
\text { Head }=\frac{R}{\sqrt{R^{2}+L^{2}}} \cdot \frac{\frac{S D \cdot L}{2 R}-S D+\sqrt{S D^{2}+2 L\left(\frac{L}{R}+\frac{R}{L}\right) \cdot \text { Groundwater }}}{\left(\frac{L}{R}+\frac{R}{L}\right)}
\end{array} \\
& \text { Inf iltExcess }=\max \left(0, \text { Throughf all }-K_{\text {Inf ilt }} l_{\text {event }}\right) \\
& \text { SatExcess }=\max (0, \text { Throughf all-Inf iltExcess }-(S C \cdot S D-\text { Groundwater }))
\end{aligned}
$$

Where $L$ and $R$ are the length and rise of the grid cell, fixed by the slope parameter and the total area per grid cell, and $S C$ and $S D$ are the soil water capacity and soil depth, respectively. This hydrological model is similar to that implemented by the Soil and Water Assessment Tool (SWAT) (Neitsch et al. 2005), minus a baseflow component (which is not relevant for the calculation of evapotranspiration). Potential evapotranspiration is assumed to be constant for forested land, and to vary linearly with the amount of grass in pastureland, so that:

$$
E V_{\text {pot }}=\left(f_{\text {past }}\left(\frac{G}{G_{\max }}\right)+f_{f o r}\right) E V_{0, p o t}
$$

where $f_{\text {past }}$ and $f_{\text {for }}$ are the fractions of land in the grid cell committed to pasture and forest, respectively, $G$ is the grass biomass, $G_{\max }$ is the grass capacity for the grid cell, and $E V_{0, p o t}$ is the nominal evapotranspiration. In this model, a grid cell fully committed to forest or filled to capacity with grass will have potential evapotranspiration of $E V_{0, p o t}$, while any consumption of grass or degradation of pasture will lead to lower potential evapotranspiration. This simple model reproduces the observed large drops in pasture potential evapotranspiration during the dry season, and the relatively stable potential evapotranspiration of forested land.

\subsection{Cattle}


Cattle are modeled with a logistic growth rate:

$$
\frac{d M}{d t}=k_{\text {cattle }} M\left(1-\frac{M}{M_{\max }}\right)
$$

where $M$ is the mass of the animal, $M_{\max }$ is the maximum mass, and $k_{\text {cattle }}$ is the intrinsic relative growth rate. It is assumed for simplicity that ranchers provide for cattle even when grass is insufficient, so that their overall growth rate is unaffected in this simulation.

\subsection{Grass}

Grass growth in each grid cell is modeled by simple carrying-capacity-limited growth, in a similar manner as cattle but with water for evapotranspiration as an additional constraint and with consumption of grass by cattle:

$$
\frac{d G}{d t}=k_{\text {grass }} G\left(1-\frac{G}{G_{\text {max }}^{*} A_{p}}\right)\left(\frac{E V_{a c t}}{E V_{p o t}}\right)-U_{\text {daily,agg }}
$$

where $G$ is the grass stock for the grid cell in $\mathrm{kg}$ dry mass, $G^{*}{ }_{\max }$ is the grass capacity per hectare and $A_{p}$ is the area in pasture, $k_{\text {grass }}$ the maximum growth rate for the cell, $E V_{\text {act }}$ the actual water available for evapotranspiration, and $U_{\text {daily,agg }}$ the total daily consumption of grass by cattle in the pasture. Note that as $A_{p}$ changes (as pasture degrades or is restored) the grass growth rate (in absolute terms) for the cell will change.

The purpose of the logistic model, as applied to both cattle and grass, is to reproduce the basics of growth - low growth rates when the cow is small (or when grass is scarce), low growth rates when the cattle is nearing maturity (or when grass is nearing capacity), and faster growth rates in between.

\subsection{Pasture degradation}

The only mechanism by which land use changes at the daily time-step scale is through pasture degradation, which occurs according to the relationship:

$$
d A_{d p}=d t \cdot A_{p}\left(\frac{1}{L_{0}}\right)\left(\frac{N}{N_{0}}\right)
$$

where $A_{d p}$ and $A_{p}$ are the areas of degraded pasture and pasture respectively, $\mathrm{L}_{0}$ is the nominal lifetime of pasture expressed as days, and $N$ and $N_{0}$ are the actual and nominal numbers of cattle on the land. This simple relationship gives a degradation rate that is inversely proportional to the nominal lifetime of the pasture (10 years, in this study) (Mattos and Uhl 1994), and directly proportional to the density of cattle in the pasture.

\subsection{Land-use change}


Ranchers base their land-use decisions on the present value of expected returns, at discount rate $d$ and over the average lifetime of a pasture, of three different options: restoring degraded pasture, clearing new forest, or restoring forest. When ranchers possess an environmental license, the expected values for each of these options are:

$$
\begin{gathered}
P V_{r, d p}(\$ / h a)=-C_{r, d p}-P V\left(C_{e, n}\right)+P V\left(I_{e, p}\right) \\
P V_{c, f}(\$ / h a)=-C_{c, f}-P V\left(C_{e, n}\right)+P V\left(I_{e, p}\right)\left(1-\Delta_{E I}\left[A_{p}+1\right] p_{m o n} \Delta p_{\text {lose }}\right) \\
P V_{r, f}(\$ / h a)=-C_{r, f}+P V\left(C_{e, n}\right)-P V\left(I_{e, p}\right)\left(1-\Delta_{E I}\left[A_{p}-1\right] p_{m o n} \Delta p_{\text {lose }}\right)
\end{gathered}
$$

When they do not possess licenses, the expected values are:

$$
\begin{gathered}
P V_{r, d p}(\$ / h a)=-C_{r, d p}-P V\left(C_{e, n}\right)+P V\left(I_{e, p}\right)\left(1-\Delta_{E I}\right) \\
P V_{c, f}(\$ / h a)=-C_{c, f}-P V\left(C_{e, n}\right)+P V\left(I_{e, p}\right)\left(\left[1-\Delta_{E I}\right]-\Delta_{E I}\left[A_{p}+1\right] \Delta p_{\text {gain }}\right) \\
P V_{r, f}(\$ / h a)=-C_{r, f}+P V\left(C_{e, n}\right)-P V\left(I_{e, p}\right)\left(\left[1-\Delta_{E I}\right]-\Delta_{E I}\left[A_{p}-1\right] \Delta p_{\text {gain }}\right)
\end{gathered}
$$

where $C$ indicates a cost, $I$ income, and $P V$ a present value. The subscript e denotes expected, and the subscripts $r, c, d p, p, f, n$ and $w c$ denote restore, clear, degraded pasture, pasture, forest, nutrient, and water charge, respectively. The bracketed expressions modifying the $P V\left(I_{e, p}\right)$ terms reflect the changes in income that result from losing or gaining the environmental license. All of the individual cost terms $\left(\mathrm{C}_{\mathrm{r}, \mathrm{dp}}, \mathrm{C}_{\mathrm{c}, \mathrm{f}}, \mathrm{C}_{\mathrm{r}, \mathrm{f}}, \mathrm{C}_{\mathrm{e}, \mathrm{n}}\right)$ above are explained in the following Cost Structure and Environmental Licensing sections.

Ranchers are able to modify up to $A_{\text {change }}$ hectares of land during each time step. If, for example, clearing new forest had the highest present value, the rancher would begin by clearing an amount of forest equal to the lesser of i) the amount of forest available to clear, ii) the amount of forest the rancher could afford to clear, or iii) the amount of land he was able to change in the time step ( $\left.A_{\text {change }}\right)$. In the case of (i) (i.e., the rancher was constrained by the amount of forest left, rather than by money or labor/time constraints), the rancher would then proceed to option with the second highest present value, and so on.

Within each grid cell, the way in which each choice is implemented spatially is different. New pastures are cleared in the order of proximity to roads. Degraded pastures are restored in the order of the severity of erosion from each grid cell (this decision is related to the dual purpose of this model in addressing issues of water quality discussed in the Purpose section). Forests are restored (ie, riparian buffers are planted) in strips of width $w_{\text {buffer }}$ in cells in the order of the severity of erosion emanating from the cell.

\subsection{Cattle stocking}

Ranching agents stock their pastures with cattle at a rate based on the average grass growth rate on their land: 


$$
\frac{d C}{d t_{\text {decision }}}=f \cdot\left(\frac{d G}{d t}\right)_{\text {ave }} \cdot \frac{A_{\text {pasture }}}{U_{\text {daily }, k g} M_{\text {cattle, avg }} t_{\text {slaughter }}}
$$

where $C$ is the stocking rate in head of cattle per hectare, $\mathrm{f}$ is a scalar multiplier (calibrated in these experiments to 2.4 - see Appendix 3), $(d G / d t)_{a v g}$ is the observed average growth rate of grass per hectare over the year, $A_{\text {pasture }}$ is the total pasture area on the property, $U_{\text {daily,kg }}$ is the nutrient requirement of cattle per $\mathrm{kg}$ of body mass per day, $M_{\max }$ is the maximum weight of cattle, $M_{\text {cattle,avg }}$ is the average weight of a head of cattle over its lifetime, and $t_{\text {slaughter }}$ is the age at which cattle are slaughtered, expressed as the number of decision intervals.

\subsection{Land sale}

We follow the approach of other agent-based rural land market models (Berger 2001, Happe et al. 2006) and allow ranchers who fall into deficit the option of putting a parcel of their land up for sale in order to fill their income gap. Ranchers begin by selling off cattle, until the cattle density on their property falls below the capacity of $(n-1)$ land cells, where $n$ is the current size of their property in grid cells. They then put up a parcel of land to potentially be sold in an auction, and continue the cycle until the revenue from cattle sold plus the potential revenue from land put up for sale offsets the current deficit. The potential revenue from land sale per hectare is estimated by the seller as the average of observed values per hectare (based on the values for land calculated by ranchers in equations A.11-A.16) communicated through the network at each timestep. The ranchers' estimates for land value stabilize during the 10-year spin-up period as they have the opportunity to sell cattle and stock land appropriately.

For each parcel in the auction, neighboring ranches that have profit to invest place a bid on the parcel equal to the shadow price of the land, given their stocking rate and cost structure, and the highest bidder wins the auction. As noted by Happe, the actual price paid for the parcel should lie somewhere between the maximum the buyer is willing to pay (the auction bid) and the minimum that the seller will accept (Happe et al. 2006). In this model, we do not have a good basis to estimate the minimum acceptable bid, since in all cases the seller is already losing money on their land; as a simplifying assumption we set the actual price paid to equal a fraction of 0.9 times the winning bid.

\subsection{Rancher cost structure}

Ranchers are subject to a number of different costs during each decision interval. Each rancher has a basic household $\operatorname{cost} \mathrm{C}_{\mathrm{h}}$ that is constant across all ranchers. Additionally, each rancher pays overhead costs that are a linear function of farm size:

$$
C_{o}=C_{o, h a} A_{\text {total }}
$$

where $C_{o}$ is estimated at about $\$ 100 /$ ha, based on the data shown in Figure A1.3. When grass growth rates are insufficient to sustain cattle on the land (interpreted in this model as whenever grass stocks drop below half of their capacity, i.e., fall below their maximum growth rate), ranchers must supplement the balance of cattle dietary needs externally at a $\operatorname{cost}$ of $C_{n}$ : 


$$
C_{n}=\sum_{\text {lots days }} \sum_{n, k g}\left(U_{\text {daily,agg }}-\left(G-G_{1 / 2}\right)\right)
$$

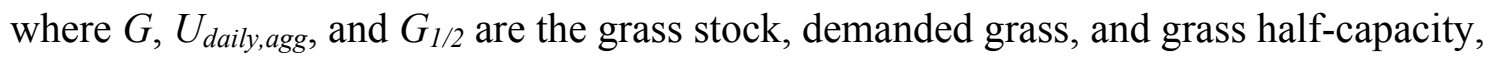
respectively, all in $\mathrm{kg}$ dry mass, and $C_{n, \mathrm{~kg}}$ is the unit cost of supplementing.

Ranchers incur costs when they change land use to clear forest or restore pasture or degraded pasture. These costs are modeled as sigmoidal functions of farm size, implying that the marginal cost of land use change decreases as farms grow in size and, presumably, become more mechanized:

$$
C_{i}=\frac{c_{\min }-c_{\max }}{l+e^{-r\left(A_{\text {actual }}-A_{\text {mech }}\right)}}+c_{\max }
$$

where $i$ denotes forest clearing, degraded pasture restoration to pasture, or pasture restoration to forest; $c_{\max }$ and $c_{\text {min }}$ are the maximum and minimum possible costs, $A_{\text {actual }}$ is the farm size, $A_{\text {mech }}$ is the midpoint of the drop in the sigmoid, interpreted here as a 'mechanization point', and $r$ is a parameter that controls the steepness of the drop. The basis for this mechanization point comes from our survey; we asked ranchers what types of technology they owned or made use of, and used tractors as an indicator of farm mechanization (Figure A1.3).

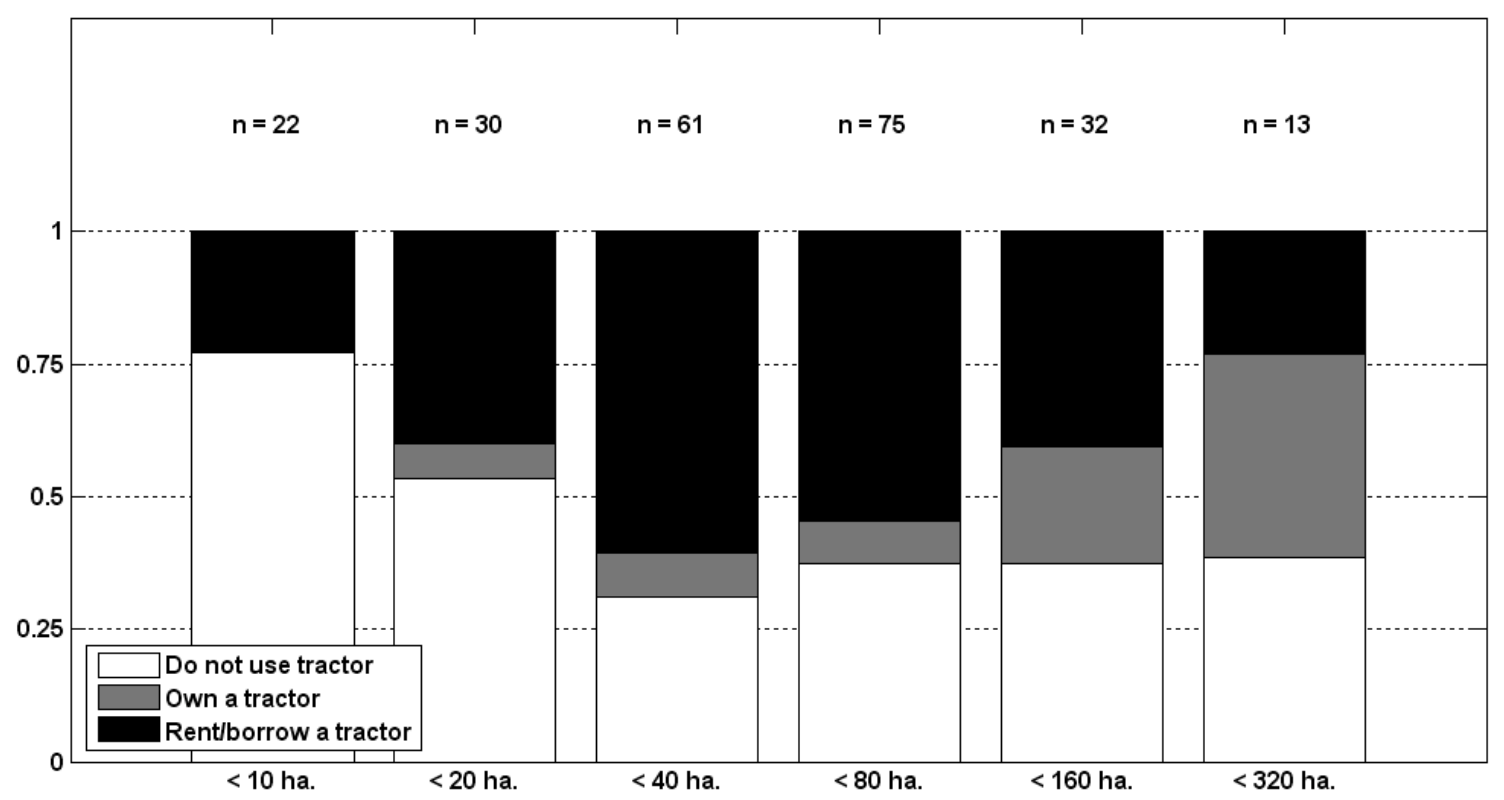

Figure A1.3: Use and ownership of tractors by survey respondents as an indicator of mechanization. The n for each bar represents the number of properties of that size in the simulation.

While ownership of tractors is clearly more limited to larger properties, even smaller properties have access to tractors - through neighbors or membership in syndicates and associations - and are able to function more efficiently. This maps into a lower cost for maintenance per hectare of land (Figure A1.4). Participants in the survey were not able to give reliable breakdowns of their annual costs to maintain their land; however, they were able to give rough estimates of the overall amount of money they had spent for maintenance in the previous year - this value, 
normalized by the land they have in pasture, is what is shown in Figure A1.4. Because, for smaller properties in particular, some land in the property is committed to more cost-intensive crops, these results should not be taken as a pure signal of how ranching costs vary across scale. They do however suggest that maintenance costs drop off quickly as ranches grow and gain access to technology such as tractors.

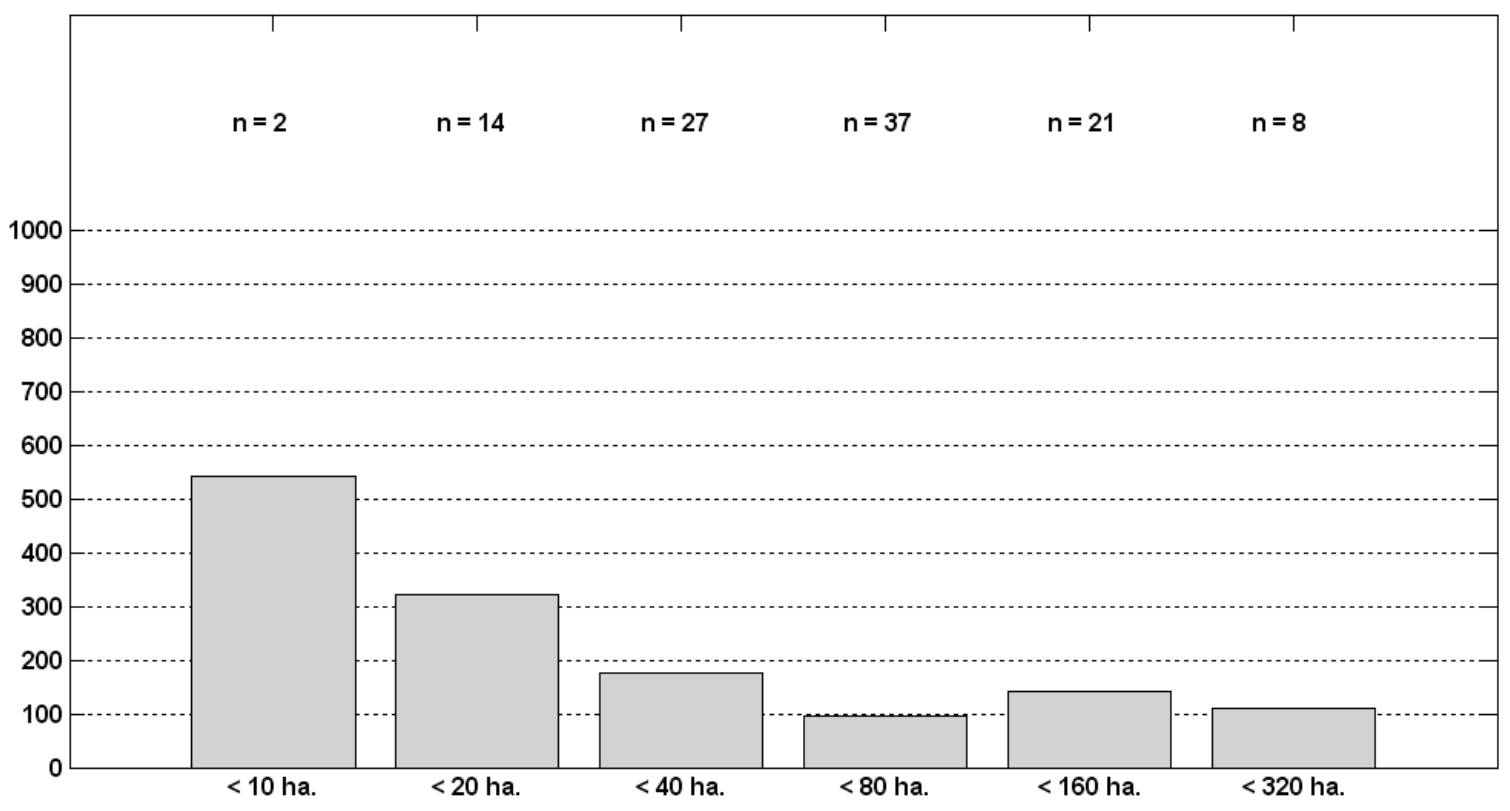

Figure A1.4: General maintenance cost per hectare per year (\$R) for properties using some fraction of land to raise cattle. Smaller properties tend also to grow crops, so that the rise in cost for smaller properties is at least partially explained by increased use of fertilizers and pesticides. The $\mathbf{n}$ for each bar represents the number of properties of that size in the simulation.

Based on visual inspection of the patterns in the use of tractors, the costs to maintain land, and the proportion of the property (Figure A1.5) that is maintained in a year, the 'mechanization point' appears to lie somewhere between 40 and 80 ha; the simulations in this study use a value of 50ha. 


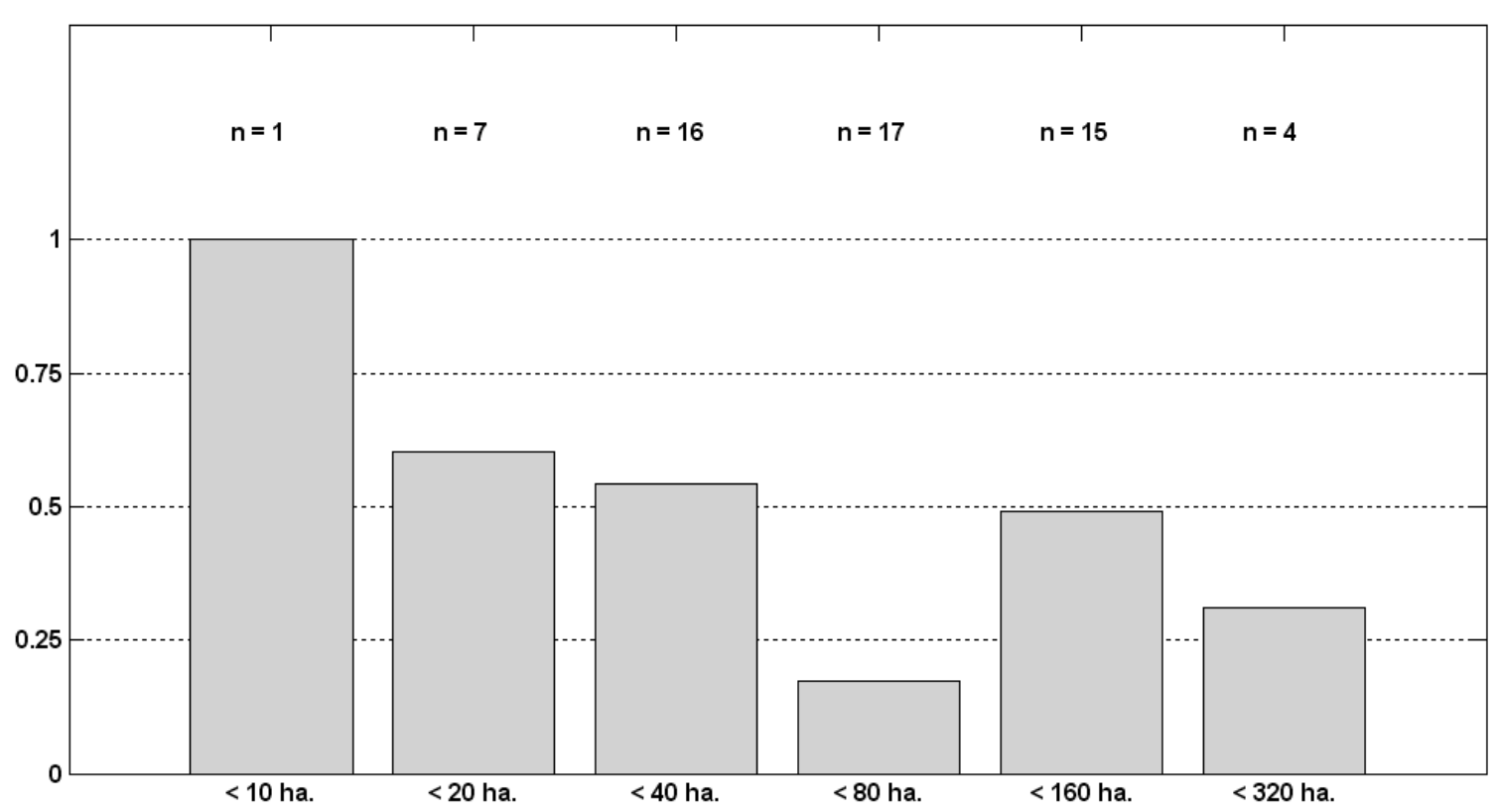

Figure A1.5: Proportion of pasture on property recuperated each year. The $n$ for each bar represents the number of properties of that size in the simulation.

This same functional form as that for the land change costs is used to evaluate the ability of a rancher to make land use change within a decision interval, although here $A_{\text {change }}$ grows as a function of farm size, to imply greater mechanization and land-use change capacity:

$$
A_{\text {change }}=\frac{A_{\text {change, } \text { max }}-A_{\text {change, min }}}{1+e^{-r\left(A_{\text {actual }}-A_{\text {mech }}\right)}}+A_{\text {change, min }}
$$

where $A_{\text {change }}$ is the area of land the rancher can modify in one decision interval, $A_{\text {actual }}$ is the size of the ranch, and $A_{\text {mech }}$ is the inflection point between non-mechanized and mechanized properties.

\subsection{Environmental Licensing}

The model for environmental licensing is simple. Ranchers are granted a license at the beginning of the simulation period, which stipulates that they must reforest their properties up to the target forest proportion $f_{\text {targ,final }}$ by the end of the management period $T$. This corresponds to a required annual rate of reforestation, and ranchers failing to reforest their properties close to the required rate run the risk of having their licenses revoked.

Rancher income changes depending on whether the rancher possesses an environmental license. Ranchers not in possession of a license have more difficulty selling their cattle, such that the overall income they receive is a proportion $\Delta_{E I}$ lower than the market price for their product. Thus, for ranchers with a license, the decision to clear a hectare of forest changes their expected income by:

$$
P V\left(I_{e, p}\right)\left(\Delta_{E I}\left[A_{p}+1\right] p_{m o n} \Delta p_{\text {lose }}\right)
$$


where $P V\left(I_{e, p}\right)$ is the expected income at market price derived from one hectare of pasture, $\Delta_{E I}$ is the proportional change in received income with a loss in license, $A_{p}+1$ is the new area of pasture following the clearing, $p_{m o n}$ is the probability of being monitored during a period and $\Delta p_{\text {lose }}$ is the change in the probability that the monitor will strip the rancher of their license, given by:

$$
\begin{gathered}
p_{\text {lose }}=\max \left(0, \frac{f_{\text {targ }, i}-f_{\text {act }}}{f_{\text {targ }, i}}\right) \\
\Delta p_{\text {lose }}=\frac{-\Delta f_{\text {act }}}{f_{\text {targ }, i}}
\end{gathered}
$$

where $f_{\text {act }}$ is the actual proportion of forested area on the property and $f_{\text {targ }, i}$ is the target forest proportion on the property for year $i$. If they fail to maintain sufficient forest land and lose their licenses, this only means that the rate of reforestation they will need in order to regain their licenses is higher each year:

$$
\Delta f_{\text {targ }, i}=\frac{f_{\text {targ, }, \text { inal }}-f_{\text {act }}}{T-t}
$$

where $\Delta f_{\text {targ, } i}$ is the proportion of new forest expected at the end of each year, $T$ is the total length of the management period, and $t$ is the current year in the management period.

Similarly, for ranchers without licenses, the decision to clear a hectare of forest changes their expected income by:

$$
P V\left(I_{e, p}\right)\left(\Delta_{E I}\left[A_{p}+1\right] p_{\text {gain }}\right)
$$

where it is assumed that $p_{m o n}$ is 1 for ranchers without licenses (i.e., they are continually monitored until the license is restored) and $\Delta p_{\text {gain }}$ is the change in the probability that the monitor will strip the rancher of their license, given by:

$$
\begin{gathered}
p_{\text {gain }}=1-\max \left(0, \frac{f_{\text {targ }, i}-f_{\text {act }}}{f_{\text {targ }, i}}\right) \\
\Delta p_{\text {gain }}=\frac{\Delta f_{\text {act }}}{f_{\text {targ }, i}}
\end{gathered}
$$

\subsection{Ranching Network}

The expected probability of being monitored $p_{m o n}$ (i.e., having a site visit) for each rancher is informed by what ranchers hear from other ranchers in the watershed. Ranchers observe the frequency that ranches are being visited as a function of their size and use this information to estimate the frequency with which their own ranch will be monitored and fined. The better the 
information they have about other ranchers in their watershed, the better their estimates of expected visit likelihoods will be.

There are a number of contributing factors to the strength of a network link between two particular ranchers - they may belong to the same rural syndicate or agricultural cooperative, they may share pastures or work together in volunteer work parties or mutirão, or they may be family, for example. Because these links are shaped by a number of different events, this study models their strength with a normal distribution. In the $g x g$ matrix $P$, where $g$ is the number of ranchers present at the start of the simulation, the strength of the link between two ranchers $i$ and $j$ is given by:

$$
P_{i j}=N\left(p_{\text {base }}, \delta p_{\text {base }}\right) \quad 0 \leq P_{i j} \leq 1
$$

where $\delta$ is the parameter for variability ( $\delta$ p gives the standard deviation) and $\mathrm{N}$ indicates a normal distribution. When rancher $i$ is fined in a given time period, $P_{i j}$ is the probability that he communicates to rancher $j$ that he was fined.

Network links may provide more than just information. Membership in syndicates and cooperatives and relationships with other ranchers may provide access to labor resources as well as equipment. In this sense, network ties may make smaller farms more resilient by allowing them to behave, from a cost perspective, more like larger farms. In this simulation, this effect is interpreted as an effective size for each farm, given by:

$$
A_{e f f i}=A_{a c t, i}+\frac{\sum_{i \neq j} P_{i j} A_{a c t, j}}{q}
$$

where $A_{\text {eff, } I}$ is the effective farm size for rancher $i$, and $q$ is a scaling factor. When $q$ is small, the contribution of other farms to the effective farm size is large; when $q$ is very large, network ties have little effect on the effective size of the farm for rancher $i$. The nature of the sigmoid curve used to model costs as a function of size means that large properties will gain little in this way, while small ranchers have more to gain by sharing resources.

\section{LITERATURE CITED}

Berger, T. 2001. Agent-based spatial models applied to agriculture: a simulation tool for technology diffusion, resource use changes and policy analysis. Agricultural Economics 25:245-260.

Grimm, V., U. Berger, F. Bastiansen, S. Eliassen, V. Ginot, J. Giske, J. Goss-Custard, T. Grand, S. K. Heinz, G. Huse, A. Huth, J. U. Jepsen, C. Jørgensen, W. M. Mooij, B. Müller, G. Pe'er, C. Piou, S. F. Railsback, A. M. Robbins, M. M. Robbins, E. Rossmanith, N. Rüger, E. Strand, S. Souissi, R. A. Stillman, R. Vabø, U. Visser, and D. L. DeAngelis. 2006. A standard protocol for describing individual-based and agent-based models. Ecological Modelling 198: 12. 
Happe, K., K. Kellermann, and A. Balmann. 2006. Agent-based analysis of agricultural policies: an illustration of the agricultural policy simulator AgriPoliS, its adaptation and behavior. Ecology and Society 11.

Mattos, M. M. and C. Uhl. 1994. ECONOMIC AND ECOLOGICAL PERSPECTIVES ON RANCHING IN THE EASTERN AMAZON. World Development 22:145-158.

Neitsch, S. L., J. G. Arnold, J. R. Kiniry, and J. R. Williams. 2005. Section 2: Hydrology. Soil and Water Assessment Tool Theoretical Documentation Version 2005. Grassland, Soil and Water Research Laboratory, Agricultural Research Service.

von Randow, C., A. O. Manzi, B. Kruijt, P. J. de Oliveira, F. B. Zanchi, R. L. Silva, M. G. Hodnett, J. H. C. Gash, J. A. Elbers, M. J. Waterloo, F. L. Cardoso, and P. Kabat. 2004. Comparative measurements and seasonal variations in energy and carbon exchange over forest and pasture in South West Amazonia. Theoretical and Applied Climatology 78:526. 


\section{Appendix 2}

\section{Sensitivity Analyses Used in Calibration}

In our model of ranching productivity, there are several key processes that shape ranch outcomes. The first is the way in which grass grows in pasture, in response to climate and land conditions. The second is the way in which grass is demanded by cattle raised on this pasture, and the third is the ability of ranchers to sell cattle and meet their income needs. In a large model such as this, there are many different parameters to assign, but many of them affect model results in similar ways. For instance, changing the maximum size reached by full grown cattle will have a similar effect on grass demand as will changing the rate at which ranchers choose to stock their lands. To make sensitivity analysis more tractable to the reader, I focus on representative variables for the three important processes given above. The responses of the ranch to climate conditions, as well as to changes in market prices, are treated already in the set of experiments of the main paper through varying $\Delta_{\mathrm{EI}}$ and $\Delta_{\mathrm{Prec}}$. It remains to look at the response of grass to different growing conditions, and the response to changing demand for grass by cattle. I look at these processes by focusing on the the intrinsic grass growth rate $k_{\text {grass }}$, pasture capacity $G_{\max }$ as indicators of grass response to growth conditions, and the scalar $f$ from the stocking rate equation (an 'aggressiveness' parameter for rancher pasture use) as an indicator of shifting demand on grass resources by cattle. The following sections present the set of real conditions to which I mean to calibrate the current model, the sensitivity results of the model outcomes to shifts in these three key parameters, and the parameter choices made in calibration.

\section{Calibration conditions}

Ranchers in our sample stocked cattle at an average of 2.78 head/ha. Smaller properties stocked more densely, reflecting a maximization of land productivity; larger properties stocked less densely, reflecting a maximization of labor productivity, a phenomenon commonly observed in rural agricultural systems (Ellis 1994, Coomes et al. 2000) (Figure A2.1). This differential use of land is shown clearly by looking at the reported rates at which ranchers recuperate their land; small ranchers report recuperating most of all of their pastures on an annual basis, while on larger properties little more than a quarter of the pasture is recuperated each year (Figure A1.4). At the reported stocking rates, ranchers reported an average cost of about \$US31 to supplement their cattle during the dry season, mostly with extra mineral salts and sugar cane leaves. 


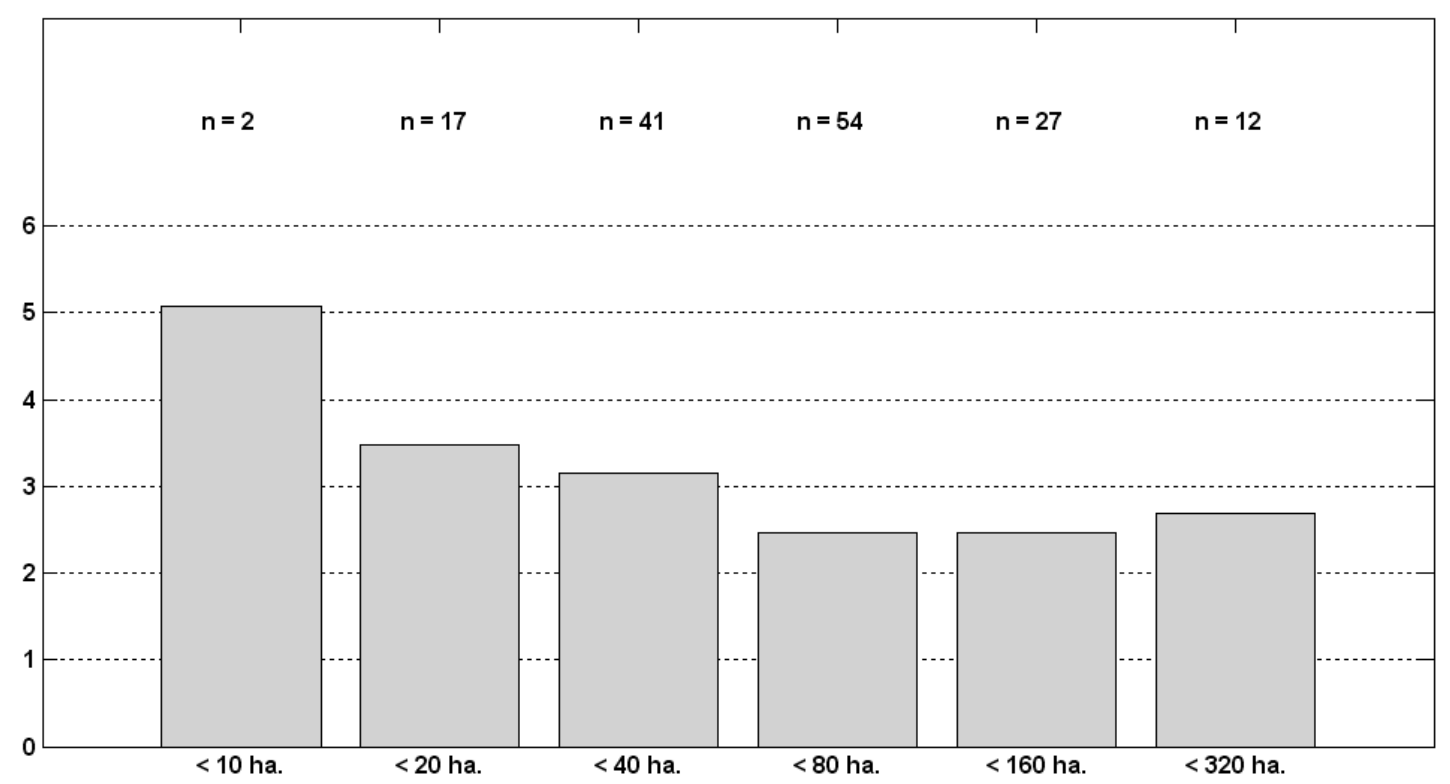

Figure A2.1: Cattle stocking density in head/ha as a function of property size. The $\mathbf{n}$ for each bar represents the number of admissable survey responses used to derive the result.

To find model parameters that best matched these conditions, we ran a three-level factorial design (Table C.1) with $\mathrm{n}=5$ repetitions along the dimensions of the intrinsic grass growth rate $k_{\text {grass }}$, pasture capacity $G_{\max }$, and scalar $f$, and took the time-averaged value over the final 10 years of each 40-year simulation of the average stocking rate and nutrient cost across all ranchers.

Table A2.1 - Parameter values for factorial design. 4 points along $k_{\text {grass }}, 5$ points along $G_{\text {max }}$, and 6 points along $f$, for a total of 120 condition sets, and 5 repetitions for a total of 600 model runs in the calibration Parameter Range

k grass

$G_{\max }$

$f$
$0.03,0.06,0.09,0.12$ $4000,5000,6000,7000,8000$

$1.6,1.8,2,2.2,2.4,2.6$

All other model parameters were set to available literature values, as described in Appendix 2. The full set of model outcomes generated by this analysis is shown below in Figures A2.2 to A2.9: 

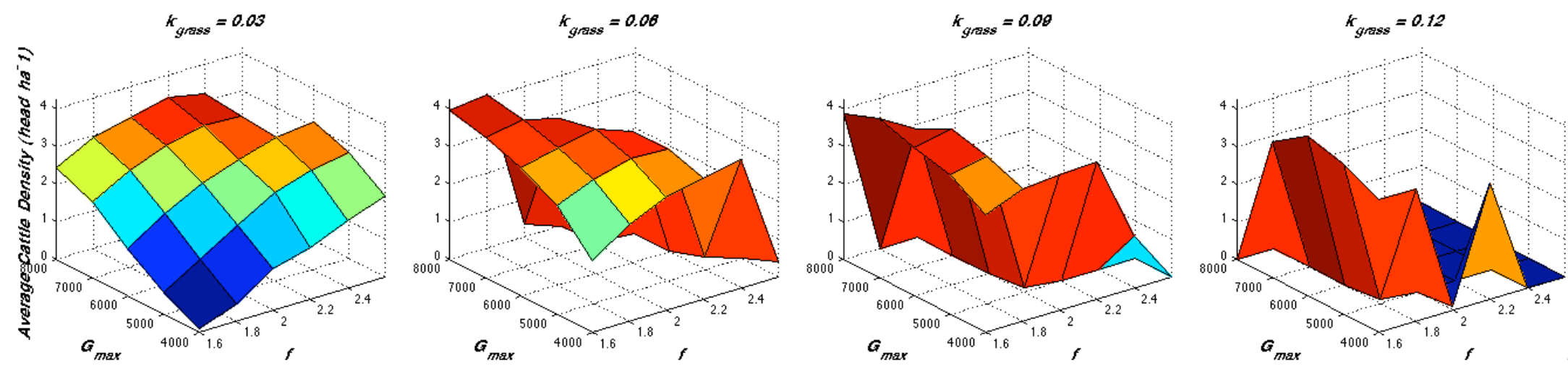

Figure A2.2: Average cattle density (head/ha) across dimensions of grass capacity $\mathbf{G}_{\max }(\mathrm{kg} / \mathrm{ha})$, scalar stocking factor $\mathrm{f}$, and maximum intrinsic grass growth rate $k_{\text {grass }}(/ t)$. Individual surfaces show average cattle density as a function of grass capacity and stocking factor $f$ at a constant intrinsic grass growth rate.
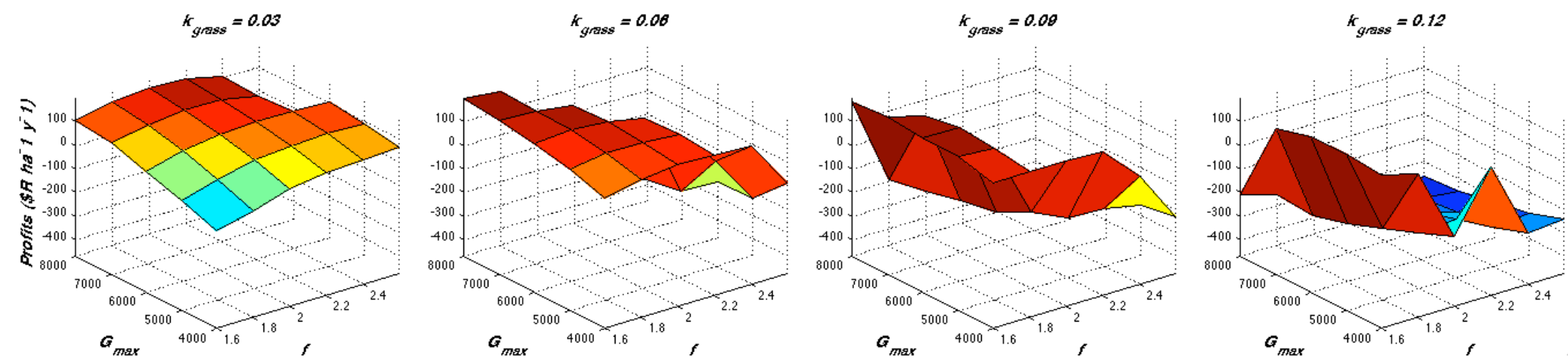

Figure A2.3: Average profits $(\$ R / h a / y)$ across dimensions of grass capacity $G_{\max }(\mathrm{kg} / \mathrm{ha})$, scalar stocking factor $\mathrm{f}$, and maximum intrinsic grass growth rate $k_{\text {grass }}(/ t)$. Individual surfaces show profits as a function of grass capacity and stocking factor $f$ at a constant intrinsic grass growth rate. 

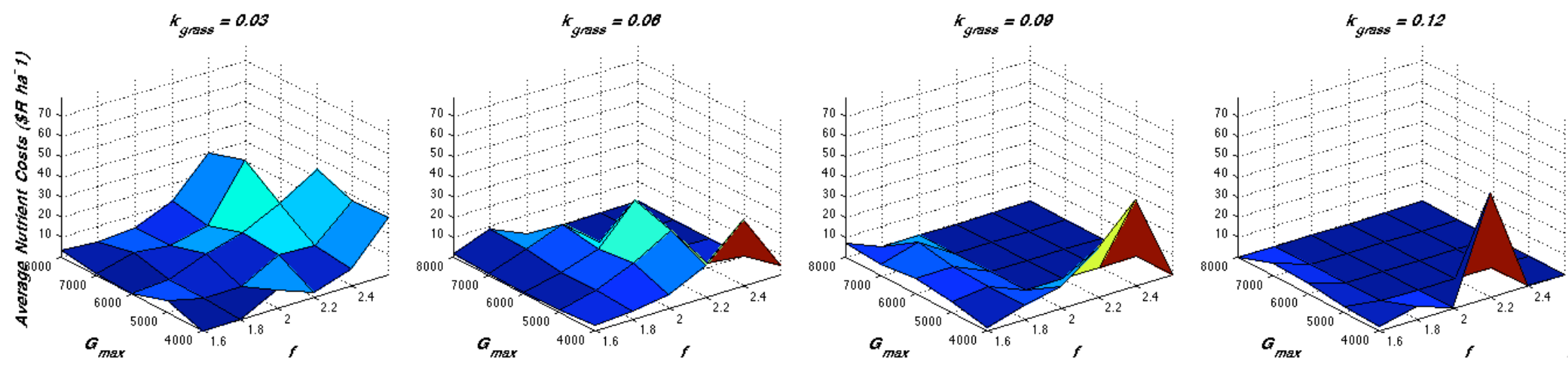

Figure A2.4: Average nutrient costs $(\$ R / h a / y)$ across dimensions of grass capacity $\mathbf{G}_{\max }(\mathrm{kg} / \mathrm{ha})$, scalar stocking factor $\mathrm{f}$, and maximum intrinsic grass growth rate $k_{\text {grass }}(/ \mathbf{t})$. Individual surfaces show average nutrient costs as a function of grass capacity and stocking factor $f$ at a constant intrinsic grass growth rate.
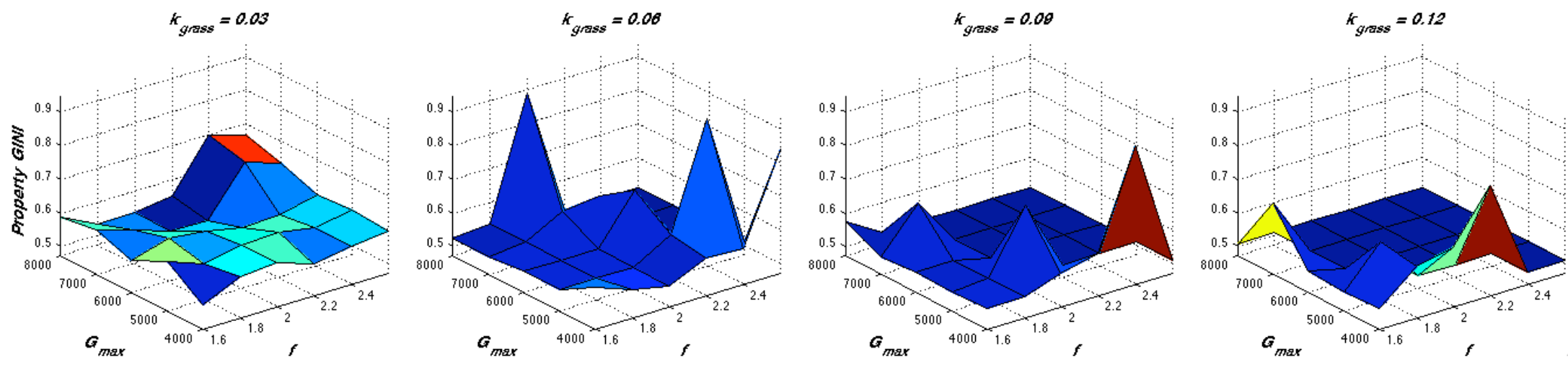

Figure A2.5: Property GINI across dimensions of grass capacity $G_{\max }(\mathrm{kg} / \mathrm{ha})$, scalar stocking factor $\mathbf{f}$, and maximum intrinsic grass growth rate $\mathrm{k}_{\text {grass }}$ $(/ t)$. Individual surfaces show GINI as a function of grass capacity and stocking factor $f$ at a constant intrinsic grass growth rate. 

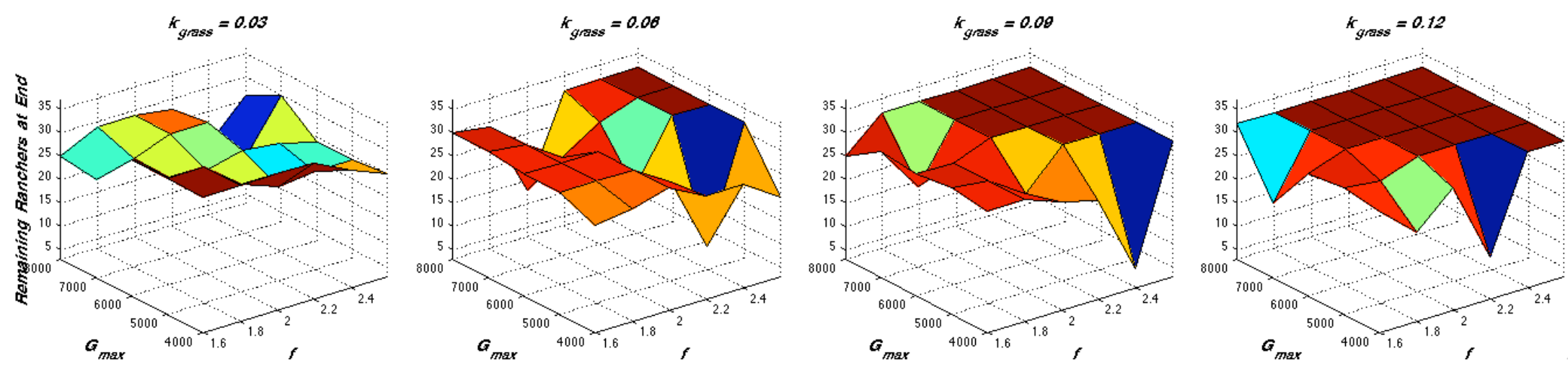

Figure A2.6: Number of ranchers remaining at end of simulation across dimensions of grass capacity $G_{\max }(\mathrm{kg} / \mathrm{ha})$, scalar stocking factor $\mathrm{f}$, and maximum intrinsic grass growth rate $k_{\text {grass }}(/ \mathbf{t})$. Individual surfaces show number of ranchers as a function of grass capacity and stocking factor $f$ at a constant intrinsic grass growth rate.
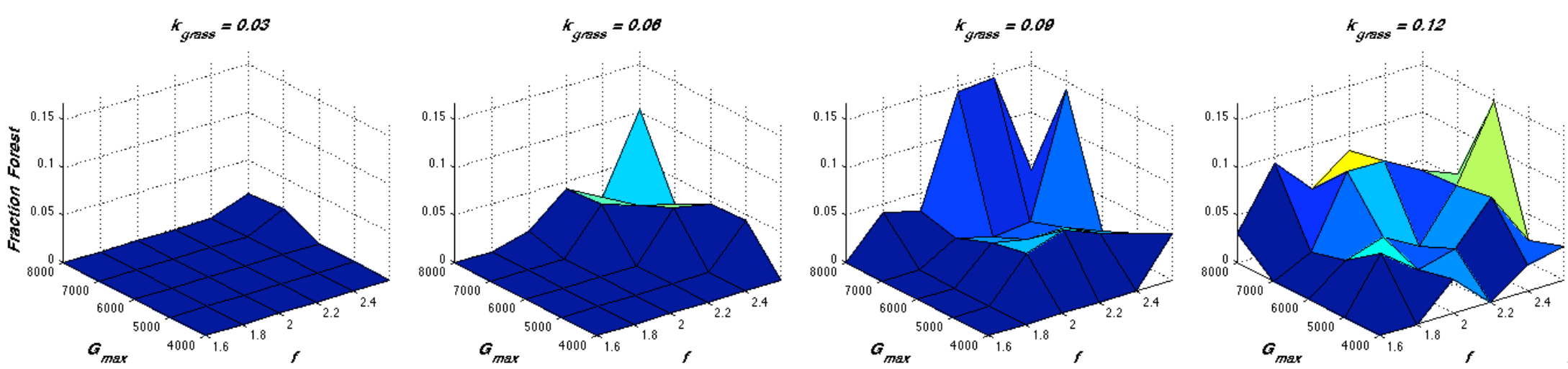

Figure A2.7: Fraction of property in forest across dimensions of grass capacity $G_{\max }(\mathrm{kg} / \mathrm{ha})$, scalar stocking factor $\mathrm{f}$, and maximum intrinsic grass growth rate $k_{\text {grass }}(/ t)$. Individual surfaces show forest fraction as a function of grass capacity and stocking factor $f$ at a constant intrinsic grass growth rate. 

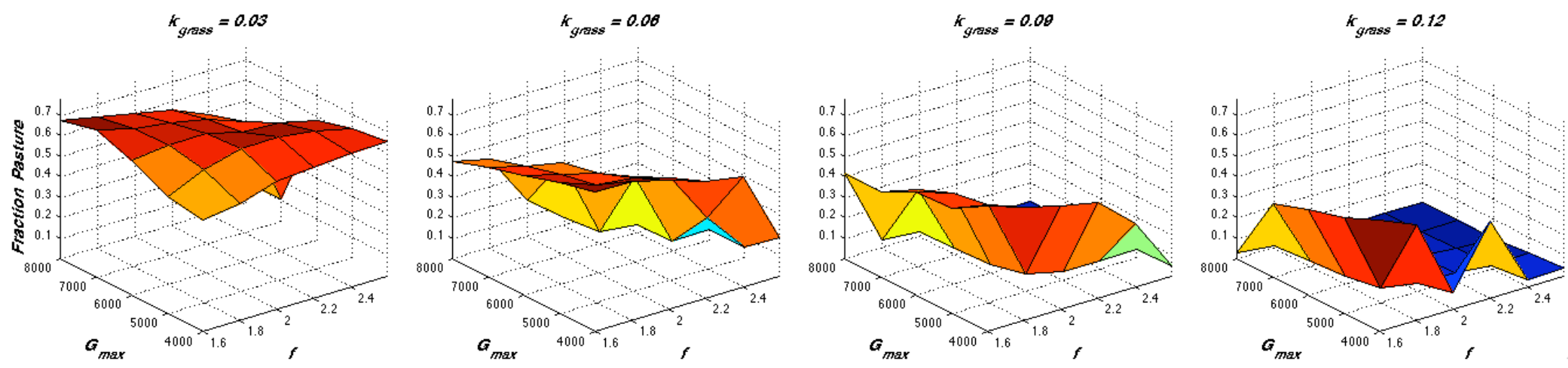

Figure A2.8: Fraction of property in pasture across dimensions of grass capacity $G_{\max }(\mathrm{kg} / \mathrm{ha})$, scalar stocking factor $\mathrm{f}$, and $\mathrm{maximum}$ intrinsic grass growth rate $\mathbf{k}_{\text {grass }}(/ \mathrm{t})$. Individual surfaces show pasture fraction as a function of grass capacity and stocking factor $f$ at a constant intrinsic grass growth rate.
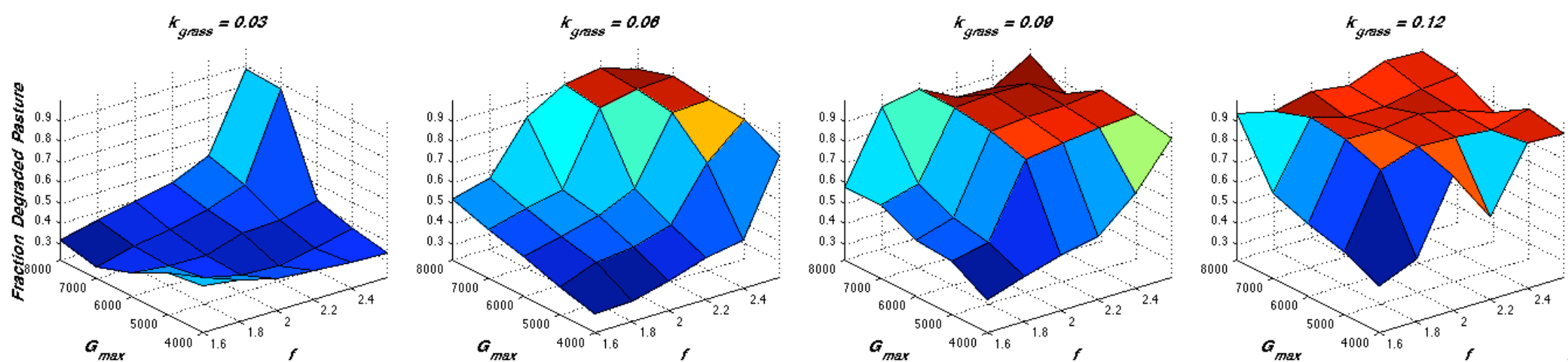

Figure A2.9: Fraction of property in degraded pasture across dimensions of grass capacity $G_{\max }(\mathrm{kg} / \mathrm{ha})$, scalar stocking factor $\mathrm{f}$, and maximum intrinsic grass growth rate $k_{\text {grass }}(/ \mathbf{t})$. Individual surfaces show degraded pasture fraction as a function of grass capacity and stocking factor $f$ at a constant intrinsic grass growth rate. 
In general, all three parameters are initially positively related to ranch profitability. However, as they rise in concert they lead ranchers to overstock and crash the ranch productivity. In the calibration effort of this study, the set of points $\left(k_{\text {grass }}=0.03 \mathrm{t}^{-1} ; G_{\max }=7 \mathrm{t} / \mathrm{ha} ; f=2.4\right)$ was chosen as the best fit to our field observed stocking rates, with average annual supplement costs of about \$US29.50, and an average stocking rate of $3.1 \mathrm{head} / \mathrm{ha}$. This parameter set corresponds to a point near the ridge before performance begins to drop in the left-most figures for the outcomes below. In other words, the observed data correspond to a locally optimal, less resilient point in the parameter space of our model.

As an independent point of comparison, Andrade et al. (2006) find capacities of 3-8 $\mathrm{t} / \mathrm{ha}$ and maximum growth rates ranging from $30-120 \mathrm{~kg} / \mathrm{ha} /$ year across different months for pastures in neighboring Acre State stocked with 2.3-3 head/ha of cattle (Andrade et al. 2006). The equivalent maximum growth rate in our study, using $k_{\text {grass }}=0.03$ and $G_{1 / 2}=3.5 \mathrm{t} / \mathrm{ha}$, is $53 \mathrm{~kg} / \mathrm{ha} /$ year (see equation A1.10).

\section{Face Validity of Modeled Ranching Activity}

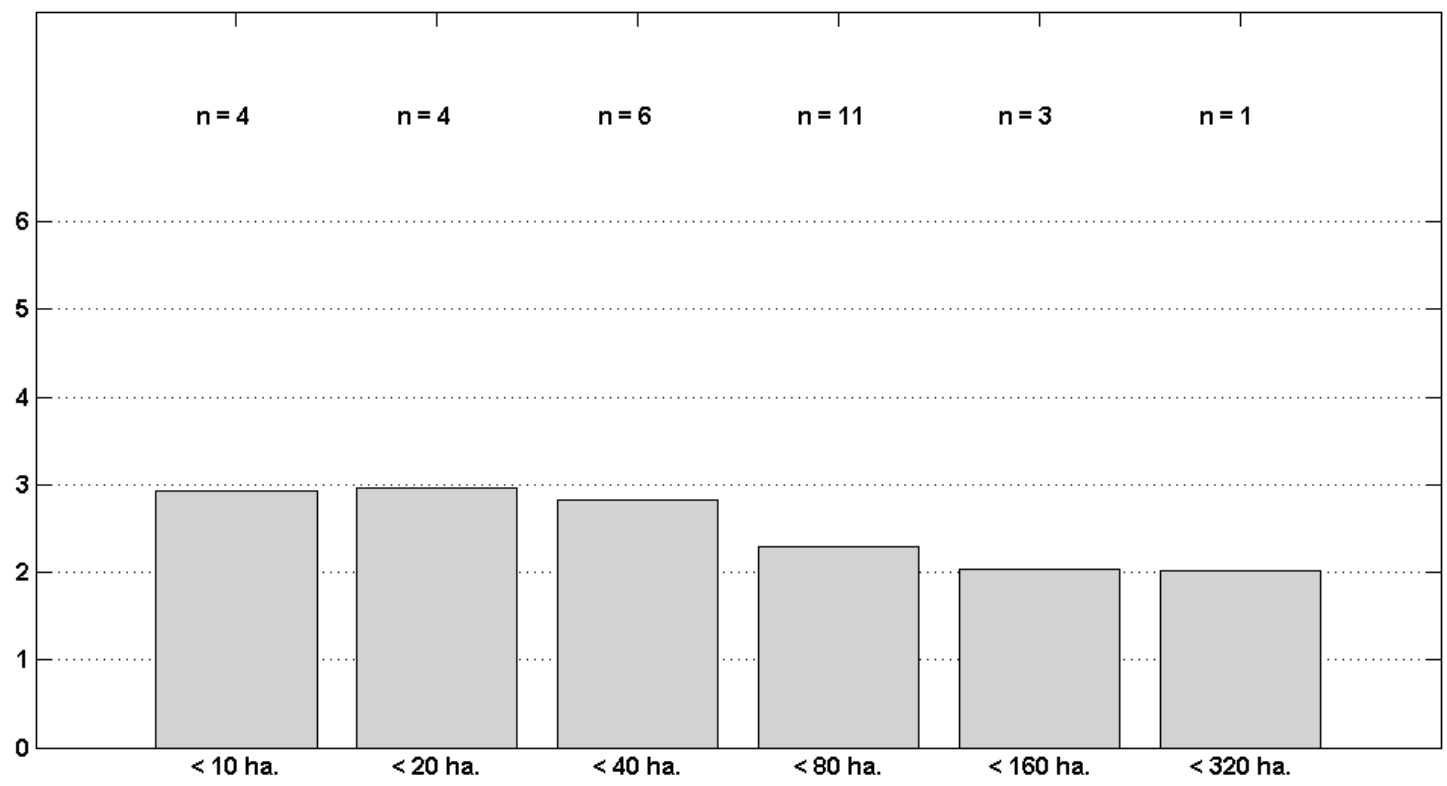

Figure A2.10: Modeled cattle stocking density in head/ha as a function of property size. The $n$ for each bar represents the number of properties of that size in the simulation.

A snapshot of a typical model run (year $7 ; \Delta_{\mathrm{Prec}}=0 ; \Delta_{\mathrm{EI}}=0$ ), as calibrated to the above conditions, shows a decrease in stocking rates as property size increases, though without the sharp increase observed for the two very small ( $<10 \mathrm{ha}$ ) properties in our sample (Figure A2.10).

The model mechanism behind this pattern lies in the limits placed on how much land a rancher can modify (in any manner) each year. This amount is modeled sigmoidally and grows from 10 ha for small properties up to 80 ha for large properties (Eq. A1.22), based on the reported areas recuperated in Figure A1.4. Pasture in the model degrades at a rate linearly proportional to cattle stocking, with a lifetime of 10 years when stocked at 1 head/ha (for comparison, Mattos and Uhl (1994) discuss a pasture lifetime of 5-10 years with respect to medium and large ranches 
stocking cattle at 0.51 and 0.66 head/ha in Pará State (Mattos and Uhl 1994). Because ranchers on smaller properties restore a greater proportion of their land each year, the amount of degraded pasture is lower, and the land is able to support a greater number of cattle; thus, stocking rates should increase with decreasing property size, a pattern which emerges in Figure A2.10.

\section{LITERATURE CITED}

Andrade, C. M. S., R. Garcia, J. F. Valentim, and O. G. P. Pereira. 2006. Grazing management strategies for massaigrass-forage peanut pastures. 3. Definition of sward targets and carrying capacity. Revista Brasileira de Zootecnia 35:352-357.

Coomes, O. T., F. Grimard, and G. J. Burt. 2000. Tropical forests and shifting cultivation: secondary forest fallow dynamics among traditional farmers of the Peruvian Amazon. Ecological Economics 32:109-124.

Ellis, F. 1994. Farm size and factor productivity. Peasant Economics: Farm households and agrarian development. Cambridge University Press, Cambridge, UK.

Mattos, M. M. and C. Uhl. 1994. Economic and Ecological Perspectives on Ranching in the Eastern Amazon. World Development 22:145-158. 


\section{Appendix 2}

\section{Agent-based Model Parameter Values for Reference Mode}

\begin{tabular}{|c|c|c|c|}
\hline Name & $\begin{array}{l}\text { Parameter } \\
\text { description }\end{array}$ & Value & Literature Values/Justifications \\
\hline$k_{\text {cattle }}$ & Cattle Growth rate & $0.5 \mathrm{~kg} / \mathrm{d}$ & $\begin{array}{r}\text { Based on an adult weight of about } 410 \mathrm{~kg} \\
\text { and a slaughter age of 4y (Mattos and } \\
\text { Uhl 1994) }\end{array}$ \\
\hline$M_{\max }$ & Max Cattle Weight & $400 \mathrm{~kg}$ & \\
\hline$p_{\text {cattle }}$ & Price, Beef & $\$ 1.5 / \mathrm{kg}$ & $\begin{array}{r}\text { Reported revenue of \$R45-60/@ (\$R3- } \\
4 / \mathrm{kg}) \text { in our sample }\end{array}$ \\
\hline$C_{r, p}$ & $\begin{array}{l}\text { Pasture Restoration } \\
\text { Cost per hectare }\end{array}$ & $\begin{array}{r}\$ 200- \\
\$ 400\end{array}$ & $\begin{array}{l}\$ 116-234 / \text { ha in } 1991 \text { (Smith et al. 1995) } \\
\$ 260 / \text { ha in } 1994 \text { (Mattos and Uhl 1994) }\end{array}$ \\
\hline$C_{r, f}$ & $\begin{array}{l}\text { APP Restoration Cost } \\
\text { per hectare }\end{array}$ & $\begin{array}{l}\$ 600- \\
\$ 1,500\end{array}$ & $\begin{array}{l}\$ 2000 / \text { ha in São Paulo State (GEF 2005) } \\
\$ 800 / \text { ha in Amazonia (Fearnside 2001) }\end{array}$ \\
\hline$C_{c, d p}$ & $\begin{array}{l}\text { APP Clearing Cost } \\
\text { per hectare }\end{array}$ & $\$ 10-\$ 50$ & Assumed \\
\hline$C_{o}$ & $\begin{array}{l}\text { Maintenance cost per } \\
\text { hectare }\end{array}$ & $\$ 100$ & Based on data presented in Appendix 1 \\
\hline$C_{h}$ & $\begin{array}{l}\text { Household Annual } \\
\text { Cost }\end{array}$ & $\$ 4000 / y$ & $\begin{array}{r}\text { An average rural monthly expense of } \\
\$ \mathrm{R} 867(\sim \$ 5500 / \mathrm{y}) \text { across Brasil, noting } \\
\text { that costs are significantly lower in the } \\
\text { North region }(\$ \mathrm{R} 1218 \text { per month overall } \\
\text { (urban }+ \text { rural) in the North vs } \$ \mathrm{R} 1778 \\
\text { for Brasil) } \\
\text { (IBGE } 2004)\end{array}$ \\
\hline$A_{\text {mech }}$ & $\begin{array}{l}\text { Logistic Function } \\
\text { Parameter }\end{array}$ & 50 ha & Based on data presented in Appendix 1 \\
\hline$r$ & Logistic Function & 0.05 & Assumed \\
\hline
\end{tabular}




\begin{tabular}{|c|c|c|c|}
\hline Name & $\begin{array}{l}\text { Parameter } \\
\text { description }\end{array}$ & Value & Literature Values/Justifications \\
\hline$C_{n, k g}$ & $\begin{array}{l}\text { Parameter } \\
\text { Cost per kg Nutrient } \\
\text { Supplement }\end{array}$ & $\$ 0.1$ & $\begin{array}{l}\text { Based on assumed grain prices of } \$ 2- \\
\text { 3/bushel; supplement costs then }\end{array}$ \\
\hline$U_{\text {daily, }, \mathrm{kg}}$ & $\begin{array}{l}\text { Nutritional Needs, } \\
\text { Cattle }\end{array}$ & $\begin{array}{r}7 \\
\mathrm{~kg} / 100 \mathrm{~kg} / \\
\mathrm{d}\end{array}$ & $\begin{array}{r}\text { calibrated to } \sim \$ 30 / \mathrm{head} / \mathrm{y} \text { under normal } \\
\text { climate conditions } \\
20-25 \mathrm{~kg} / \mathrm{animal} / \mathrm{d}(\mathrm{NRC} 2001)\end{array}$ \\
\hline$A_{\text {change }}$ & $\begin{array}{l}\text { Maximum Land Use } \\
\text { Change Rate }\end{array}$ & $10-80 \mathrm{ha} / \mathrm{y}$ & $\begin{array}{l}\text { Based on data presented in Appendix } 1 \\
\text { Assumed. Reasonable values estimated } \\
\text { from SIGTERON Soil Profile database } \\
\text { (Cochrane and Cochrane 2006) }\end{array}$ \\
\hline$S C$ & Soil Water Capacity & $40 \mathrm{~cm} / \mathrm{m}$ & \\
\hline$S D$ & Soil Depth & $0.5 \mathrm{~m}$ & \\
\hline$(R / L)$ & Slope Grade & $5 \%$ & \\
\hline$K_{\text {infilt } f}$ & $\begin{array}{l}\text { Soil Infiltration Rate, } \\
\text { Forest }\end{array}$ & $\begin{array}{r}1500 \\
\mathrm{~mm} / \mathrm{h}\end{array}$ & $1533 \mathrm{~mm} / \mathrm{h}$ (Zimmermann et al. 2006) \\
\hline$K_{\text {infilt }, p}$ & $\begin{array}{l}\text { Soil Infiltration Rate, } \\
\text { Pasture }\end{array}$ & $120 \mathrm{~mm} / \mathrm{h}$ & $122 \mathrm{~mm} / \mathrm{h}$ (Zimmermann et al. 2006) \\
\hline$K_{\text {sat }, f}$ & Forest saturated flow & $200 \mathrm{~mm} / \mathrm{h}$ & $206 \mathrm{~mm} / \mathrm{h}$ (Zimmermann et al. 2006) \\
\hline$K_{\text {sat }, p}$ & $\begin{array}{l}\text { Pasture saturated } \\
\text { flow }\end{array}$ & $20 \mathrm{~mm} / \mathrm{h}$ & $26 \mathrm{~mm} / \mathrm{h}$ (Zimmermann et al. 2006) \\
\hline$l_{\text {event }}$ & $\begin{array}{l}\text { Mean Rain Event } \\
\text { Length }\end{array}$ & $1 \mathrm{~h}$ & $\begin{array}{l}\text { An operational variable to generate } \\
\text { realistic hourly rainfall intensities from } \\
\text { modeled daily rainfall distributions. } \\
\text { Estimated from precipitation data for Ji- } \\
\text { Paraná (ANA 2009) }\end{array}$ \\
\hline$L_{0}$ & $\begin{array}{l}\text { Nominal Pasture } \\
\text { Lifetime }\end{array}$ & 10 years & 5-10 years (Mattos and Uhl 1994) \\
\hline $\begin{array}{l}d t_{\text {decision }} \\
d\end{array}$ & $\begin{array}{l}\text { Decision Interval } \\
\text { Discount Rate }\end{array}$ & $\begin{array}{l}1 \mathrm{y} \\
5 \%\end{array}$ & $\begin{array}{l}\text { Assumed } \\
\text { Assumed }\end{array}$ \\
\hline
\end{tabular}

\section{LITERATURE CITED}

ANA. 2009. Sistema de Monitoramento Hidrológico. Agencia Nacional de Àguas - ANA. Cochrane, T. T. and T. A. Cochrane. 2006. Diversity of the Land Resources in the Amazonian State of Rondônia, Brazil. Acta Amazonica 36:91-102.

Fearnside, P. M. 2001. Land-tenure issues as factors in environmental destruction in Brazilian Amazonia: The case of Southern Para. World Development 29:1361-1372.

GEF. 2005. GEF Project Document on a Proposed Grant fro the Global Environment Facility Trust Fund in the amount of USD 7.75 Million to the State of São Paulo for a Ecosystem Restoration of Riparian Forests in São Paulo Project. Global Environment Facility. IBGE. 2004. Pesquisa de Orçamentos Familiares (POF) 2002-2003. IBGE.

Mattos, M. and C. Uhl. 1994. Economic and Ecological Perspectives on Ranching in the Eastern Amazon. World Development 22:145-158. 
NRC. 2001. Dry Matter Intake. Page 408 Nutrient Requirements of Dairy Cattle. National Academy Press, Washington, D.C., USA.

Smith, N. J. H., E. A. S. Serrão, P. T. Alvim, and I. C. Falesi. 1995. Amazonia - Resiliency and Dynamism of the Land and its People. United Nations University Press, Tokyo, Japan.

Zimmermann, B., H. Elsenbeer, and J. M. De Moraes. 2006. The influence of land-use changes on soil hydraulic properties: Implications for runoff generation. Forest Ecology and Management 222:29-38. 


\section{Appendix 4. Full Results for Different Rancher Scenarios}

(Erratum: The caption for this appendix should read "MATLAB Source Code")

Please click here to download file 'appendix4.zip'. 


\section{Appendix 5}

\section{Full Results for Different Rancher Scenarios}

Results are presented beginning on the following page in landscape format 

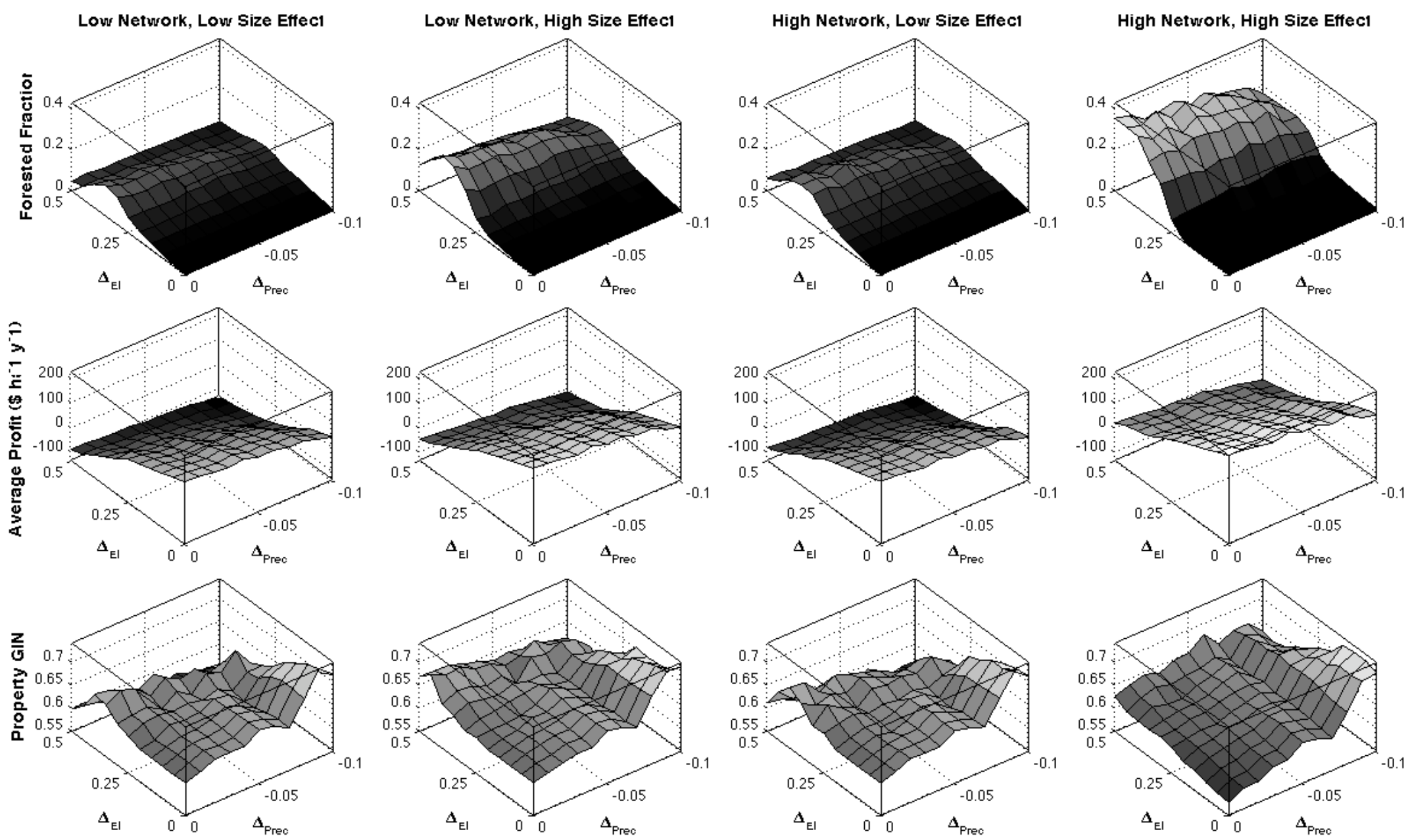

Figure A5.1: Response surfaces for Policy Scenario 1 - Sensitivity to change in expected income $\Delta_{\mathrm{EI}}$ and in precipitation $\Delta_{\text {Prec }}$, non-tiered environmental licensing. Surfaces in row 1 show average forested fraction across the landscape; row 2 shows average profit per hectare of property per year; row 3 shows the level of land aggregation measured by the property GINI coefficient. Each column represents a different scenario of rancher interaction. 

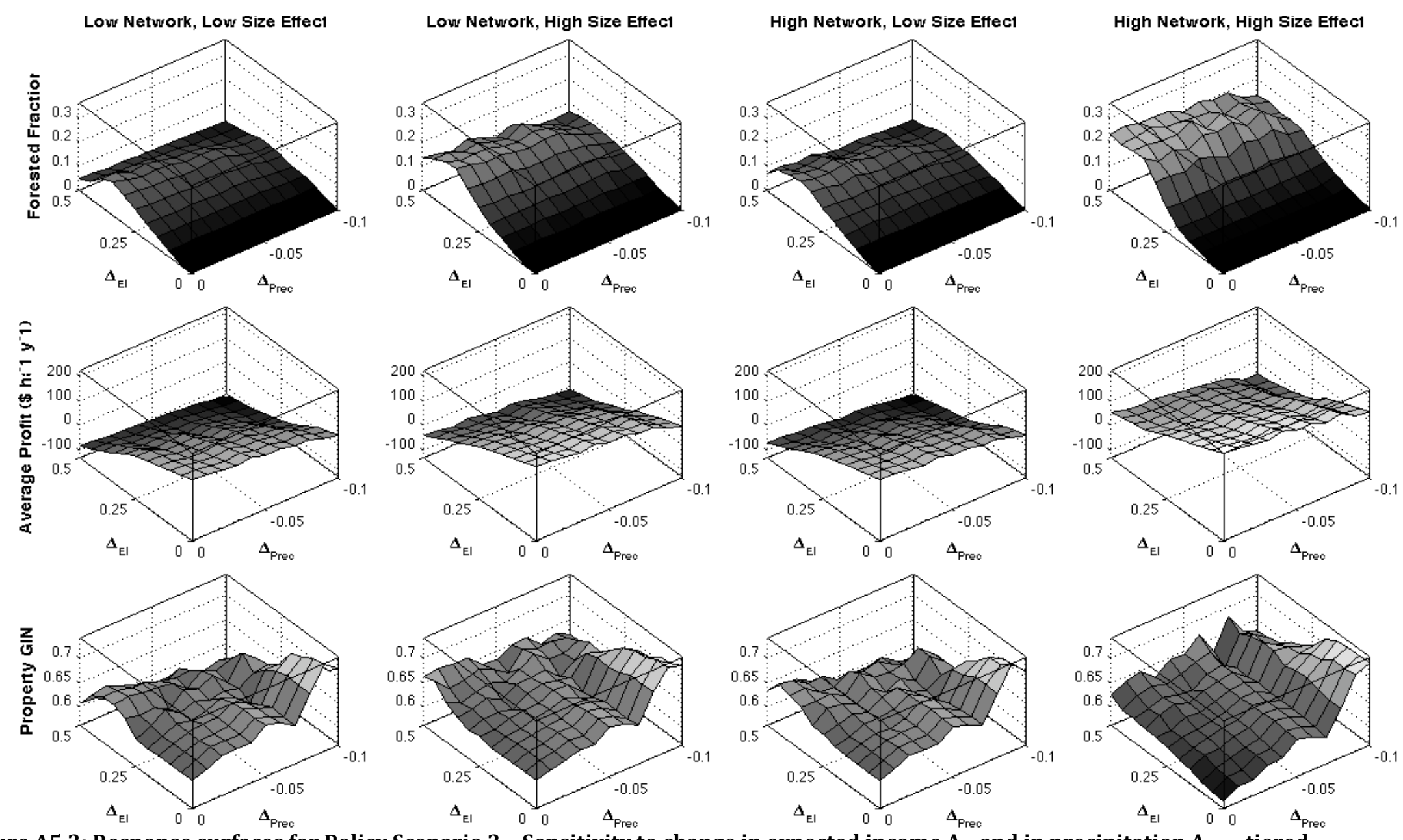

Figure A5.2: Response surfaces for Policy Scenario 2 - Sensitivity to change in expected income $\Delta_{\mathrm{EI}}$ and in precipitation $\Delta_{\text {Prec }}$ tiered

environmental licensing. Surfaces in row 1 show average forested fraction across the landscape; row 2 shows average profit per hectare of property per year; row 3 shows the level of land aggregation measured by the property GINI coefficient. Each column represents a different scenario of rancher interaction. 

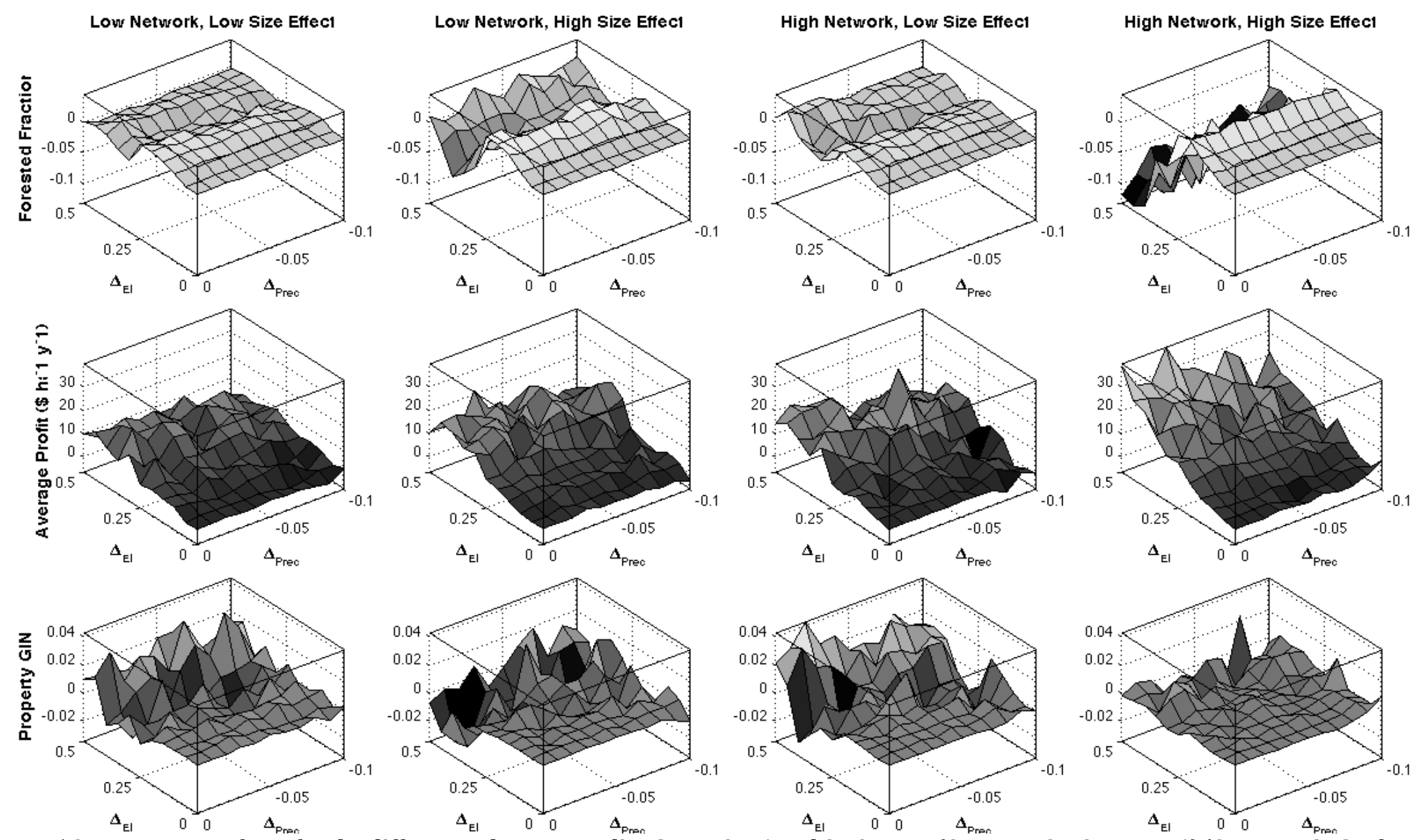

Figure A5.3: Response surfaces for the differences between Policy Scenarios 1 and 2, given as (Outcome 2 - Outcome 1)/Outcome 2. Surfaces in row 1 show difference in average forested fraction across the landscape; row 2 shows difference in average profit per hectare of property per year; row 3 shows difference in the level of land aggregation measured by the property GINI coefficient. Each column represents a different scenario of rancher interaction. 

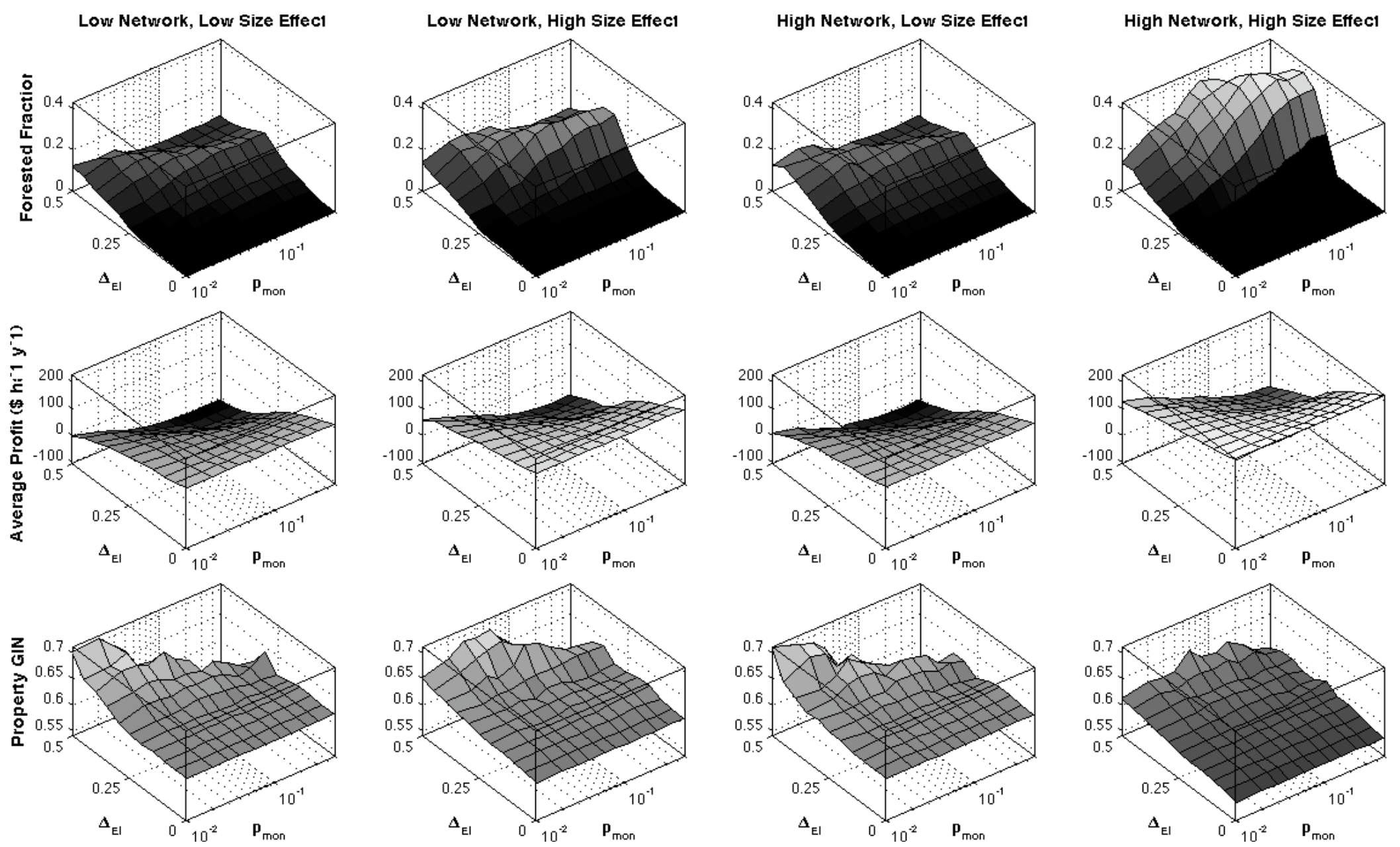

Figure A5.4: Response surfaces for Policy Scenario 3 - Sensitivity to change in expected income $\Delta_{\mathrm{EI}}$ and in monitoring probability $p_{\mathrm{mon}}$, nontiered environmental licensing. Surfaces in row 1 show average forested fraction across the landscape; row 2 shows average profit per hectare of property per year; row 3 shows the level of land aggregation measured by the property GINI coefficient. Each column represents a different scenario of rancher interaction. 

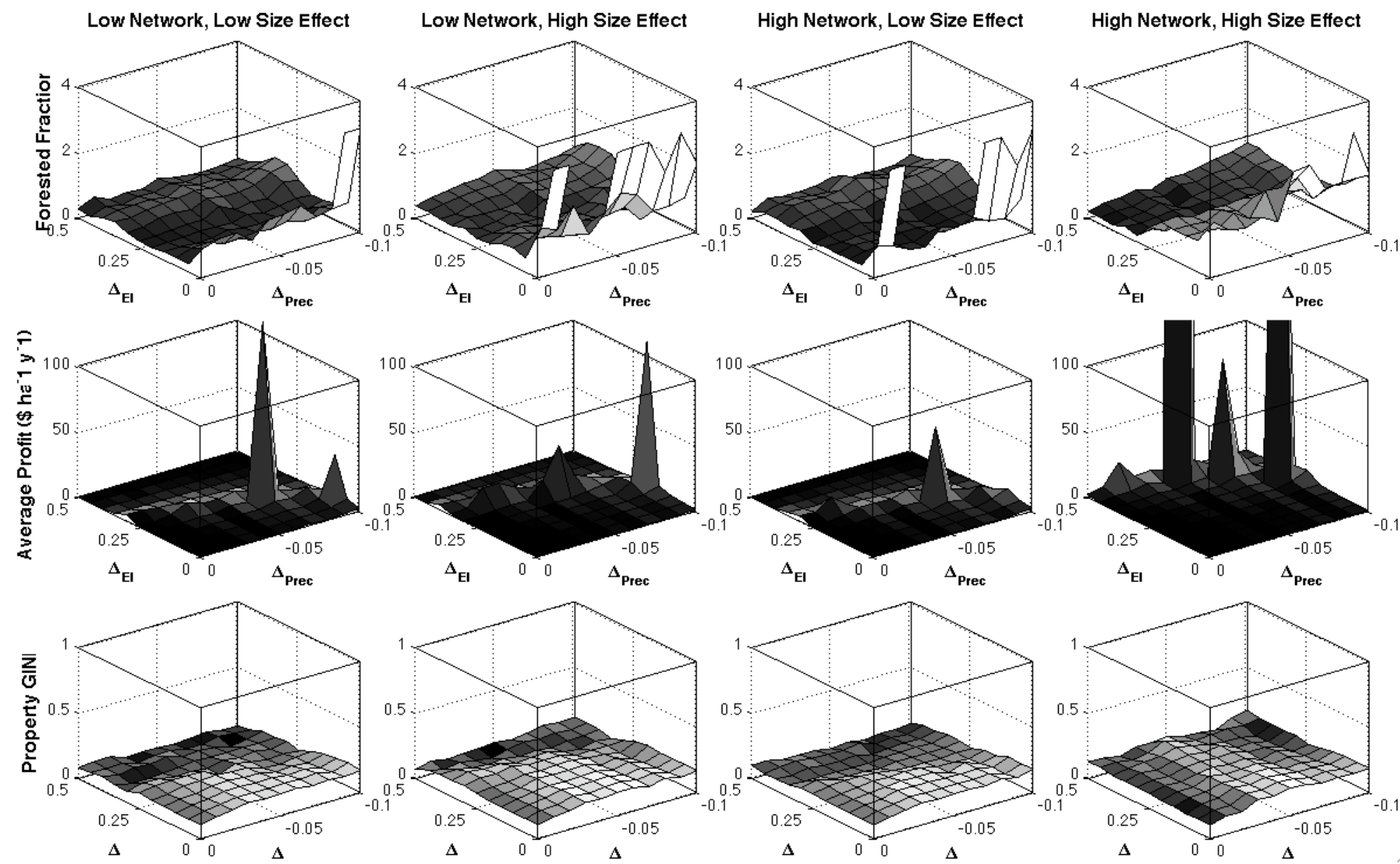

Figure A5.5: Standard deviations for response surfaces for Policy Scenario 1 - Sensitivity to change in expected income $\Delta_{\mathrm{EI}}$ and in

precipitation $\Delta_{\text {Prec }}$, non-tiered environmental licensing. Surfaces in row 1 show standard deviation for forested fraction across the landscape; row 2 shows standard deviation for profit per hectare of property per year; row 3 shows the standard deviation for level of land aggregation measured by the property GINI coefficient. Each column represents a different scenario of rancher interaction. Values reflect the standard deviation across $\mathbf{n}$ replicates, divided by the mean across the $\mathbf{n}$ replicates. 

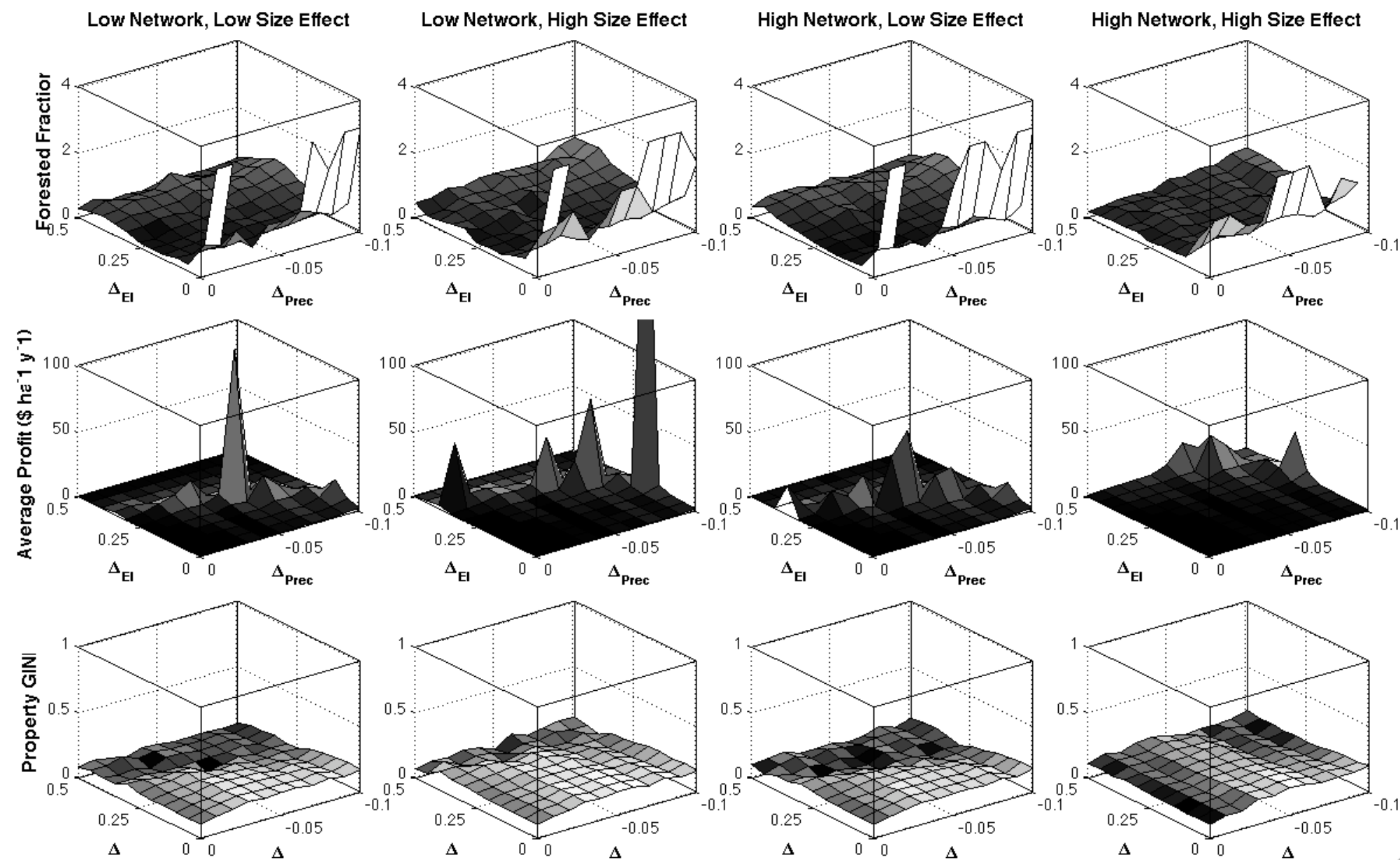

Figure A5.6: Relative standard deviations for response surfaces for Policy Scenario 2 - Sensitivity to change in expected income $\Delta_{\mathrm{EI}}$ and in precipitation $\Delta_{\text {Prec }}$, tiered environmental licensing. Surfaces in row 1 show standard deviation for forested fraction across the landscape; row 2 shows standard deviation for profit per hectare of property per year; row 3 shows the standard deviation for level of land aggregation measured by the property GINI coefficient. Each column represents a different scenario of rancher interaction. Values reflect the standard deviation across $\mathbf{n}$ replicates, divided by the mean across the $\mathbf{n}$ replicates. 

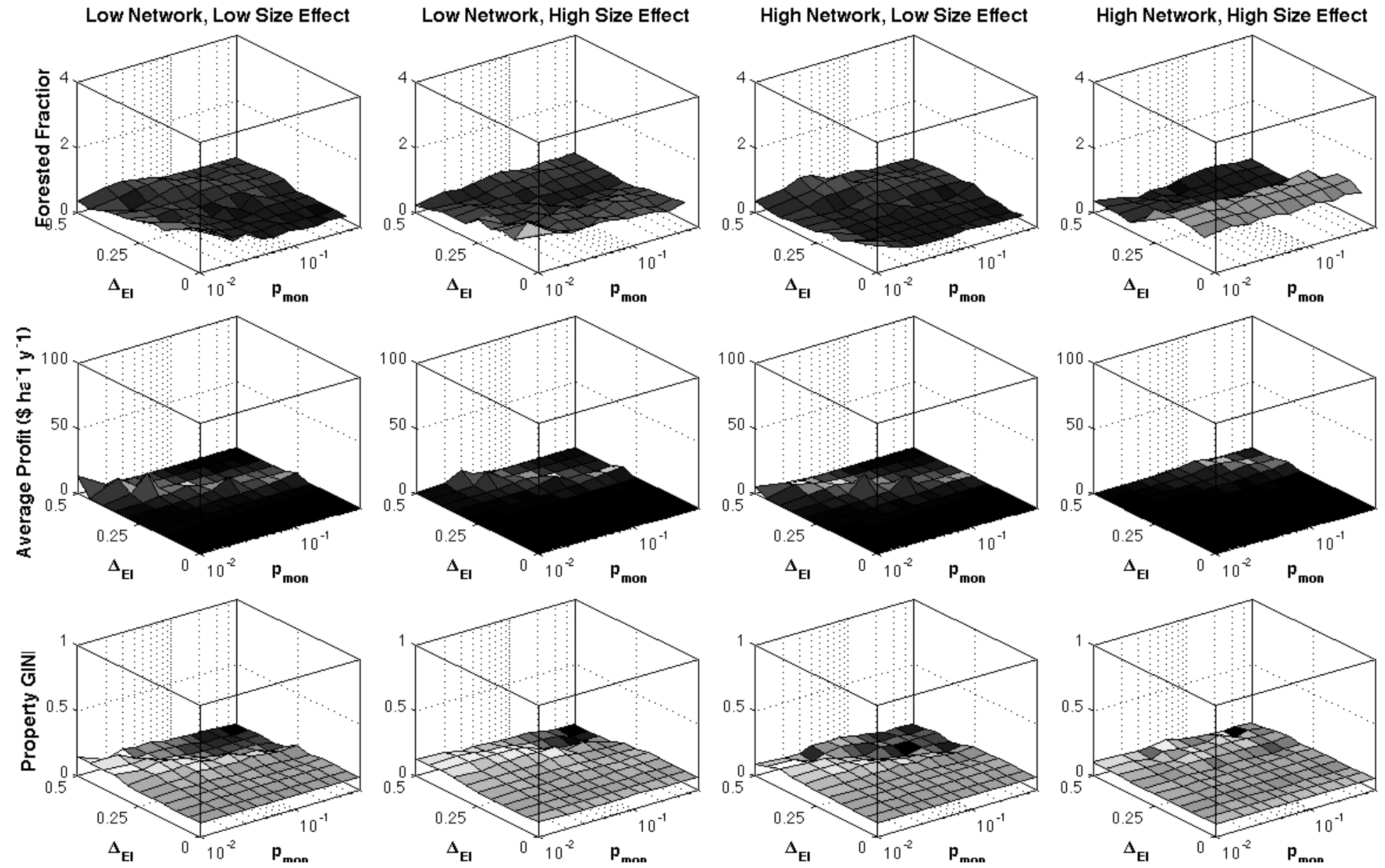

Figure A5.7: Standard deviations for response surfaces for Policy Scenario 3 - Sensitivity to change in expected income $\Delta_{\mathrm{EI}}$ and in monitoring probability $p_{m o n}$, non-tiered environmental licensing. Surfaces in row 1 show standard deviation for forested fraction across the landscape; row 2 shows standard deviation for profit per hectare of property per year; row 3 shows the standard deviation for level of land aggregation measured by the property GINI coefficient. Each column represents a different scenario of rancher interaction. Values reflect the standard deviation across $\mathbf{n}$ replicates, divided by the mean across the $\mathbf{n}$ replicates. 